\title{
Komani (Dalmace, Albanie). Bilan de la mission franco-albanaise de la campagne 2016
}

Etleva Nallbani, Yann Bonfand, Sophie Vatteoni et Elvana Metalla

\section{(2) OpenEdition Journals}

Édition électronique

URL : http://journals.openedition.org/cefr/2357

DOI : $10.4000 /$ cefr.2357

ISSN : 2282-5703

Éditeur

École française de Rome

Référence électronique

Etleva Nallbani, Yann Bonfand, Sophie Vatteoni et Elvana Metalla, « Komani (Dalmace, Albanie). Bilan de la mission franco-albanaise de la campagne 2016 », Chronique des activités archéologiques de l'École française de Rome [En ligne], Balkans, mis en ligne le 04 février 2019, consulté le 09 août 2019. URL: http://journals.openedition.org/cefr/2357 ; DOI : 10.4000/cefr.2357

Ce document a été généré automatiquement le 9 août 2019

(c) École française de Rome 


\title{
Komani (Dalmace, Albanie). Bilan de la mission franco-albanaise de la campagne 2016
}

\author{
Etleva Nallbani, Yann Bonfand, Sophie Vatteoni et Elvana Metalla
}

1 La campagne de terrain 2016 à Komani a réuni les auteurs de cet article ainsi que H. Sokoli (archéologue, Directorat régional de la culture nationale de Shkodra), W. Boutenbat (doctorante-allocataire en archéologie, université Paris IV), H. Monchot (archéozoologie, Labex RESMED), E. Neri (chercheur CDD au CNRS/UMR 5060 IRAMATCEB), M.-P. Raynaud (UMR 8167/Orient et Méditerranée), U. Tota (doctorant, université d'Avignon et l'Institut d'Archéologie de Tirana), O. Durmishaj (archéologue, Parc archéologique d'Apollonia), A. Léger (topographe, INRAP), D. Margjoni (restaurateur, Directorat régional de la culture nationale de Shkodra), E. Bitri, D. Dubois (restaurateurs, profession libérale), Gj. Gjuraj (Directorat régional de la culture nationale de Durrës) et A. Bici (étudiant en master d'archéologie, université de Lorraine).

2 L'opération de terrain s'est déroulée sur quatre semaines, du 4 juillet au 3 août 2016. Elle s'est concentrée sur un seul secteur du site, celui de la partie basse (zone 1B) de la colline dite "de la citadelle» (fig. 1). Cette opération fait suite à la grande entreprise de dégagement de l'église identifiée lors de la campagne de 2013, qui depuis a concentré de nombreux efforts. D'une taille assez conséquente $-17 \mathrm{~m}$ de longueur - et pourvue d'élévations insoupçonnées, l'église est caractérisée par une architecture atypique dont la succession des différentes phases soulève de nombreux questionnements. Par ailleurs, c'est l'aménagement de sa nef et l'incroyable richesse picturale qui constitue la découverte majeure de l'opération de 2016. Ce fut l'occasion de définitivement mettre au jour et de fouiller toute la nef et le bas-côté nord. Au regard des contraintes et de l'ampleur de la tâche, le dégagement définitif du chœur a été reporté à la campagne de 2017. 
Fig. 1 - Plan des différentes zones du site (vue Google).

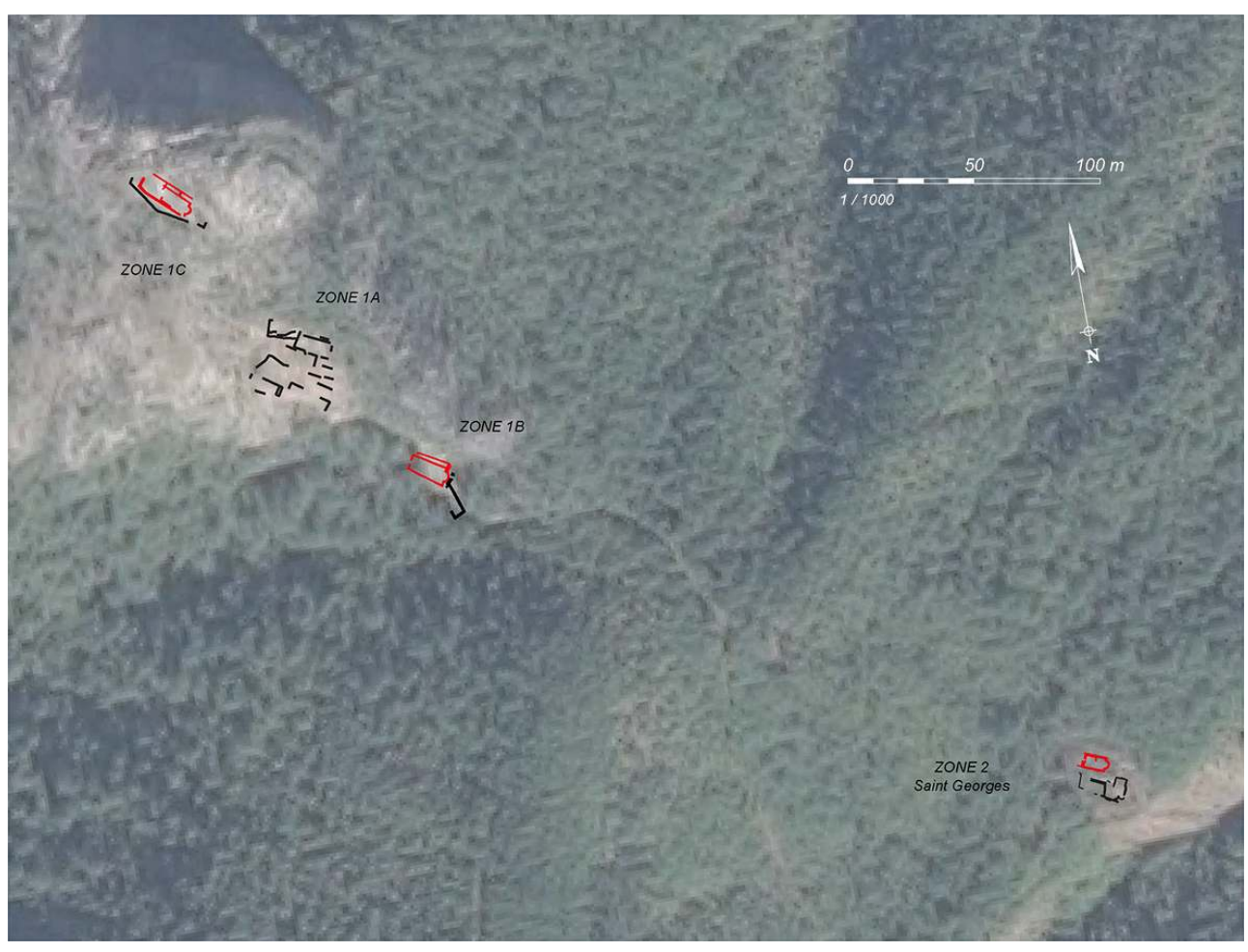

DAO A. Léger, S. Vatteoni.

\section{Rappel des opérations précédentes}

Les campagnes précédentes avaient concentré l'effort à la mise au jour du bâtiment rectangulaire à l'est de l'église. À l'église même, il a été dégagé davantage son mur est, l'abside ainsi que l'intérieur du collatéral, autant d'éléments qui ont pu permettre de caractériser la nature du bâtiment. La fouille des niveaux du collatéral a pu, quant à elle, donner à la fois une idée de l'ampleur de l'édifice et la mesure des élévations conservées. Au niveau du sanctuaire, l'église disposait des aménagements liturgiques : synthronon de deux marches flanquant un trône central et deux installations liturgiques de part et d'autre de l'abside (fig. 2, prise en 2014). 
Fig. 2 - Église, zone 1B. Vue sur le synthronon et l'installation liturgique nord-est.

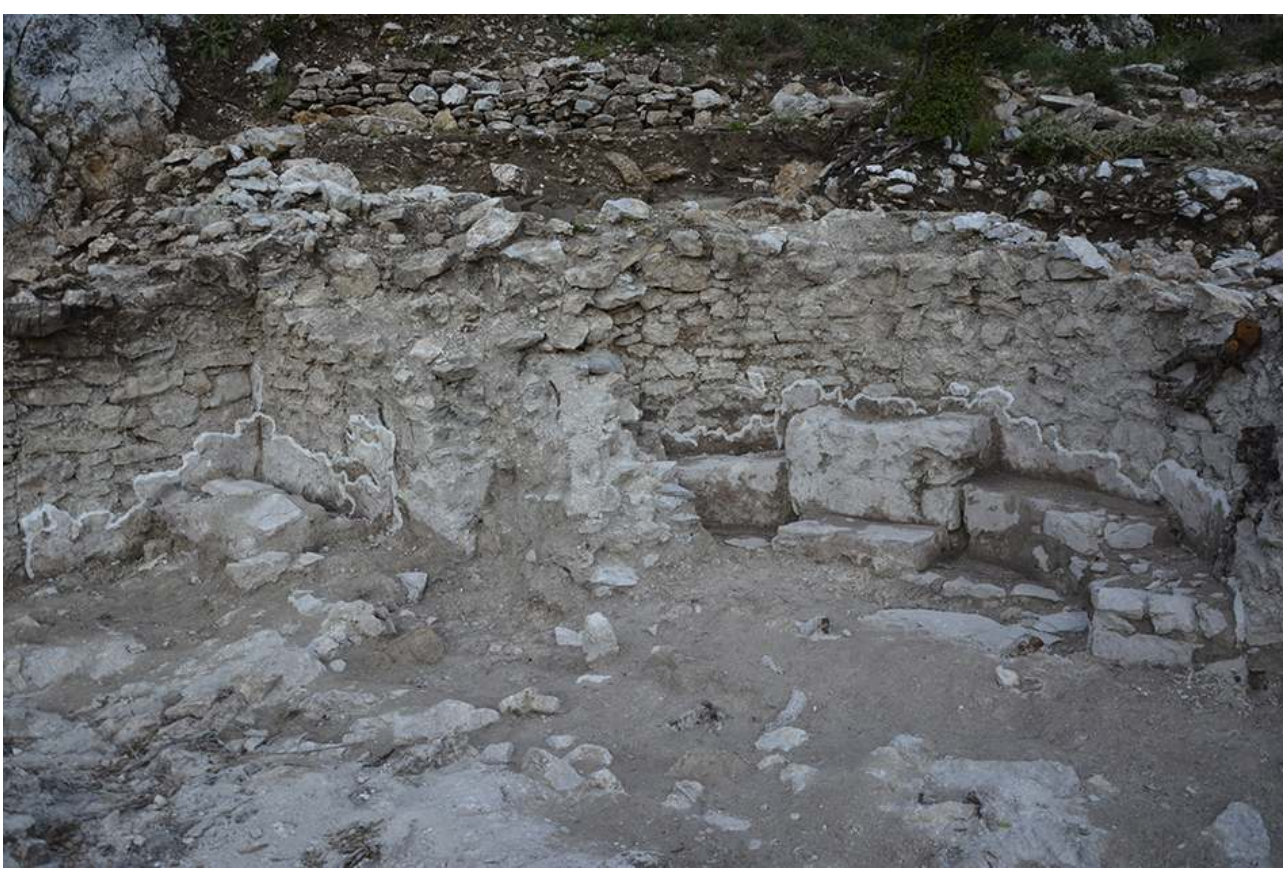

Cl. K. Lilo.

4 Afin d'identifier l'intégralité du monument et ses éléments composants, distinguer les différents états chronologiques de l'église et mieux comprendre sa fonction funéraire, et face à l'ampleur des volumes et la complexité du terrain, cinq sondages ont été effectués aux points stratégiques (fig. 3) : 
Fig. 3 - Église, zone 1B. Plan schématique de l'église, l'emplacement des tombes et des sondages engagés en 2015.

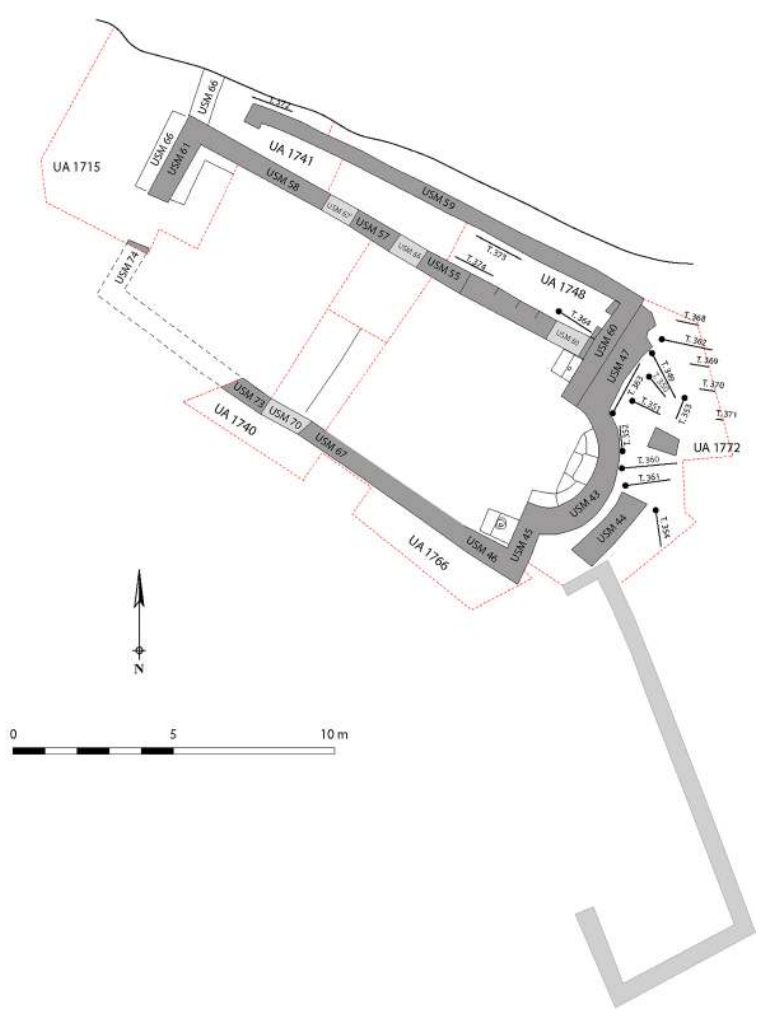

Topographie et DAO S. Vatteoni

5 - Le sondage 1715. Localisé à l'extrémité nord-ouest de l'église, ce sondage d'environ $5,50 \times 5,50 \mathrm{~m}$ visait à mettre au jour le parement extérieur du mur de façade, le but étant d'atteindre l'entrée principale à l'Ouest. Il a permis de découvrir tout le pignon nordouest de $70 \mathrm{~cm}$ d'épaisseur, très bien conservé, portant des traces de peinture sur sa surface externe ; l'angle sud du pignon a été arraché par la descente d'un très gros bloc ( fig. 4) ; l'angle nord-ouest a été également dégagé jusqu'au 1,5 $\mathrm{m}$ en direction de l'est, à l'intérieur de la nef. L'entrée principale positionnée à l'ouest, large de 1,20 m, était précédée de la roche naturelle taillée devant le seuil, lui-même arraché. Des installations liturgiques sont apparues : un banc maçonné haut de $40 \mathrm{~cm}$ occupe l'angle nord-ouest de la nef centrale. En forme de L, il se poursuit fort probablement sur le mur nord, dont la longueur a été suivie seulement sur 1,50 m vers l'est. Le banc est couvert du même enduit de qualité très fine que celui qui couvre entièrement le synthronon. Un autre banc, de $45 \mathrm{~cm}$ d'hauteur du sol, se positionne sur toute la longueur du pignon nord-ouest de l'église, couvrant la peinture de la façade (fig. 5). Il s'agirait ainsi d'un aménagement plus tardif par rapport à cette phase de l'église comportant la façade externe peinte. 
Fig. 4 - Église, zone 1B. Vue sur la nef depuis l'Ouest, avec le rocher mis en évidence.

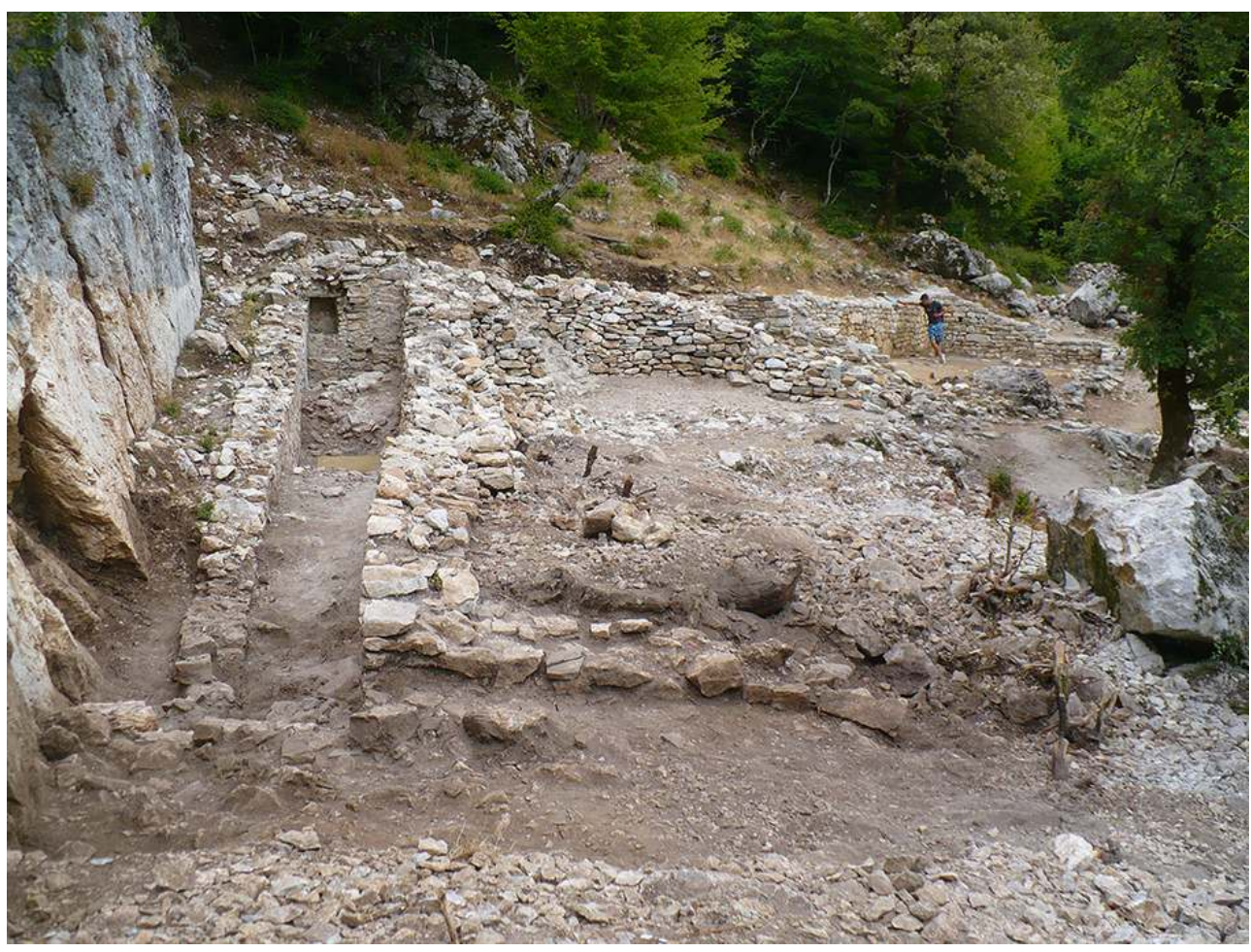

Cl. Y. Bonfand.

Fig. 5 - Église, zone 1B. Banquette 1843 - Sondage 1715.

Koman $2015 \quad$ Minute 4 $23 / 08 / 2015$

YB

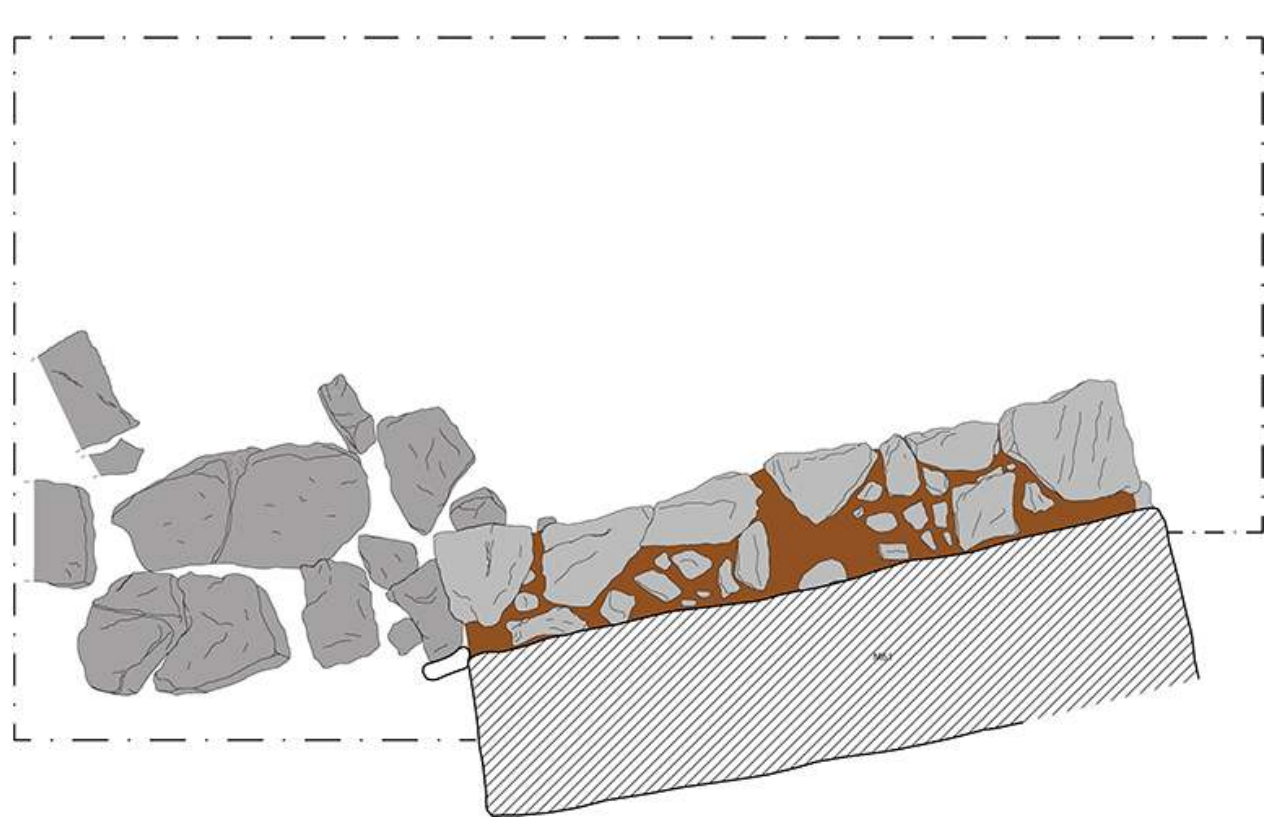

DAO Y. Bonfand 
6

- Le sondage 1741, quasiment jointif au sondage 1715, s'est engagé entre la falaise et le mur nord de la nef, à l'entrée du collatéral ; l'aménagement de pierres qui, désaxé vers l'Ouest, joint l'angle nord-ouest de l'église à la falaise presque dans la poursuite du mur de façade M61, constitue la séparation (US 1842). La fouille n'a pas permis de déterminer si cet aménagement constitue un mur de bouchage venant condamner l'accès au collatéral ou s'il s'agit d'un escalier lui donnant accès. De fait, cet aménagement s'inscrit dans le fonctionnement du collatéral qu'il favorise, en le desservant, ou condamne.

- Le sondage 1740 avait pour but de connaître simultanément plusieurs éléments de la nef: la succession, via le parement intérieur, de l'alternance murs-bouchages, déjà observée dans le mur du collatéral; le barlong sud, observé lors de la phase de déblaiement des vestiges superficiels ; deux baies ont été perçues, et le niveau de sol de la nef. Ainsi, une tranchée d'environ $2 \mathrm{~m}$ de large a été plantée perpendiculairement à la nef et approximativement localisée en son centre. La fenêtre ainsi ouverte a permis de concentrer les efforts de fouille sur un espace limité afin de retirer un maximum d'informations et d'établir des coupes (fig. 6). De fait, outre la couverture de dalles en ardoise, avec des restes des éléments de la charpente, et le niveau de sol, ce sondage fut l'occasion de la mise au jour d'une marche dans l'alignement de l'ouverture dans le mur sud (fig. 7).

Fig. 6 - Église, zone 1B. Sondage 1740, dans la nef centrale.

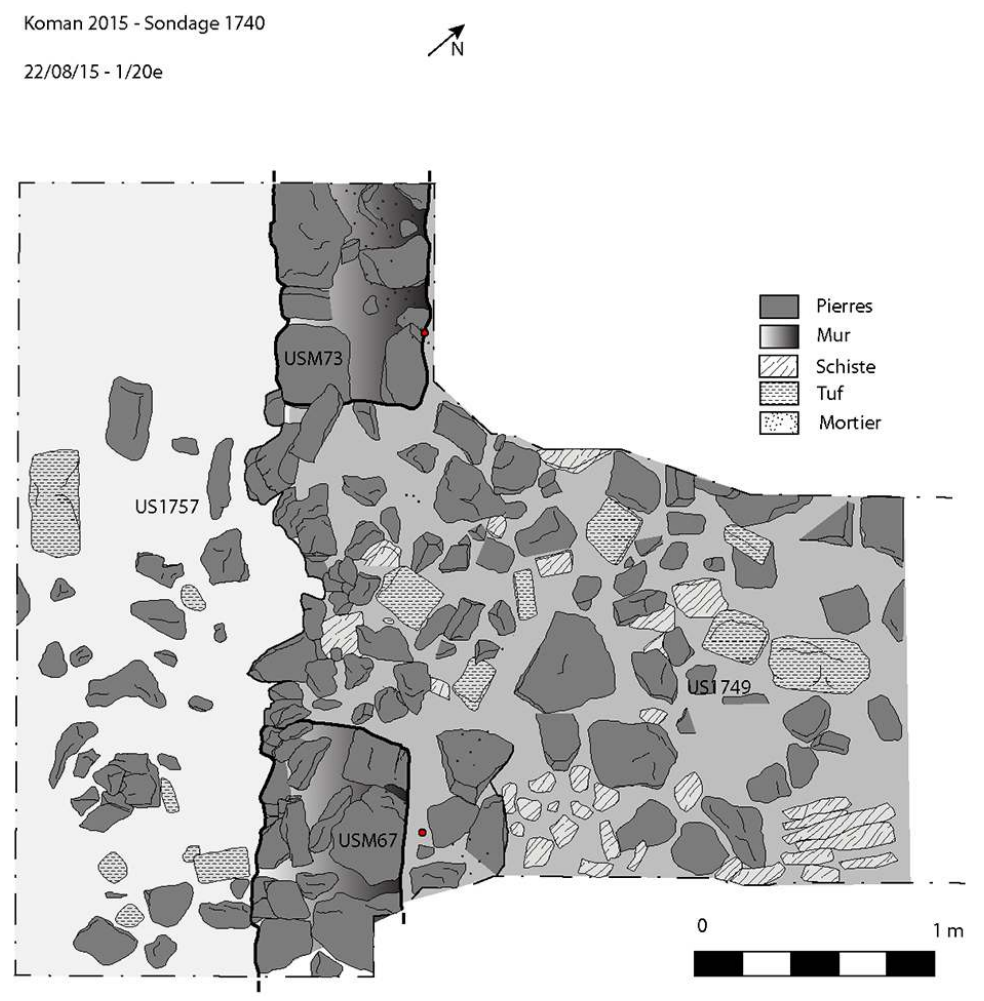

DAO Y. Bonfand.

Chronique des activités archéologiques de l'École française de Rome , Balkans 
Fig. 7 - Église, zone 1B. Baie ouest (US 1783) du mur M46 et marche 1781 lors de son déblaiement en 2015.

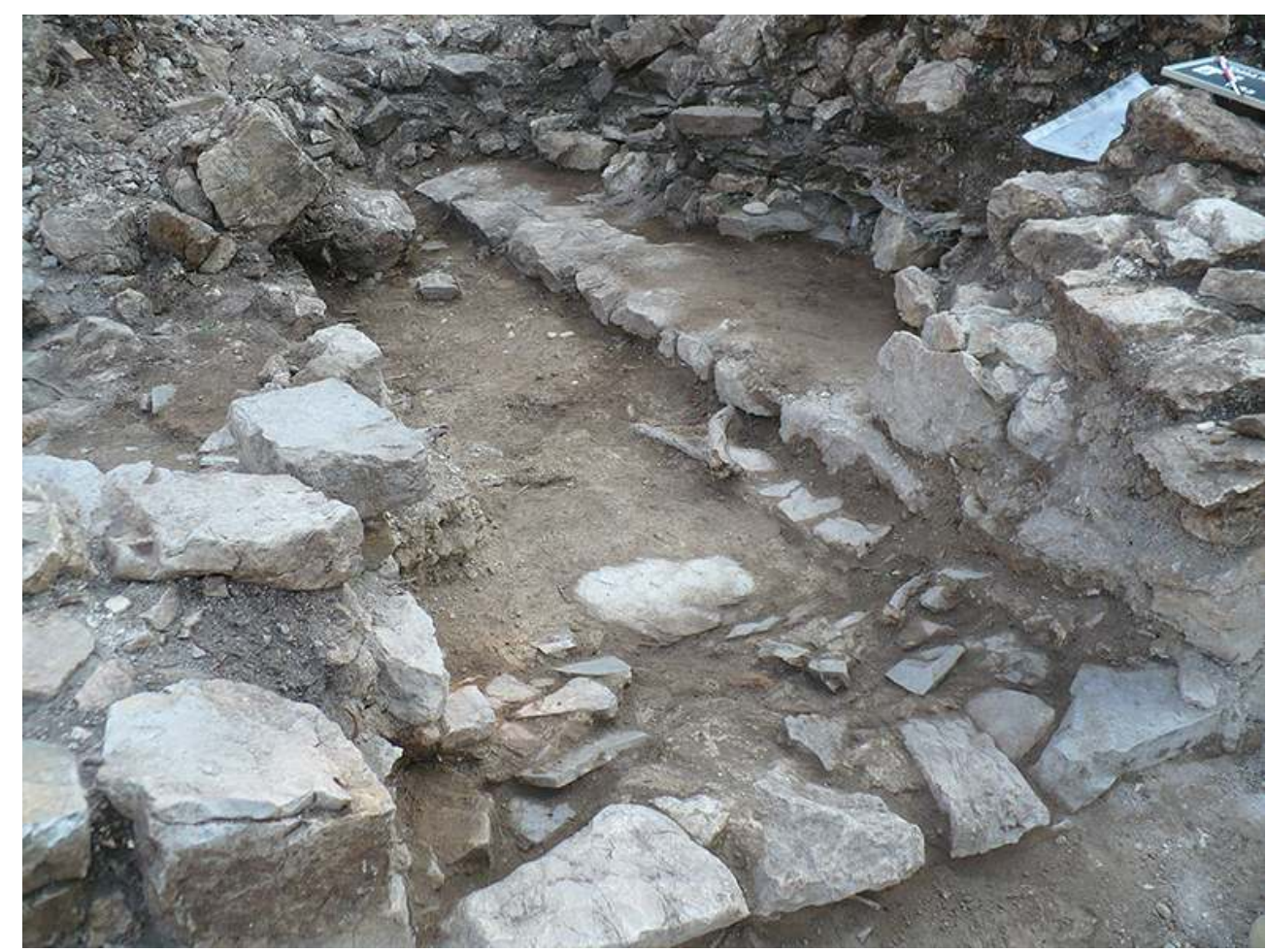

Cl. Y. Bonfand.

Pour mieux comprendre la poursuite du barlong sud et en éventuelle installation symétrique au collatéral nord, le sondage a été agrandi en direction de l'Ouest, sur $4 \mathrm{~m}$ de longueur contre le parement extérieur du mur sud.

Deux autres sondages l'ont complété, dont le 1766 , ouvert sur près de $5,50 \mathrm{~m}$, afin de vérifier à la fois l'angle externe sud-est de la nef. Effectivement l'église est une construction asymétrique, pourvue d'un seul collatéral nord. Un niveau de piétons suit sur le barlong sud sur toute sa longueur du sondage, matérialisé par de grosses dalles polies.

Le sondage 1748, localisé à l'autre extrémité du collatéral, celui du nord-est, a nécessité au préalable de retirer les très grosses pierres qui en obstruaient l'accès (fig. 8). Il s'est avéré que le collatéral recélait de nombreuses inhumations qui ont nécessité l'intervention des anthropologues. 
Fig. 8 - Église, zone 1B. Pierre dans le collatéral en cours de dégagement.

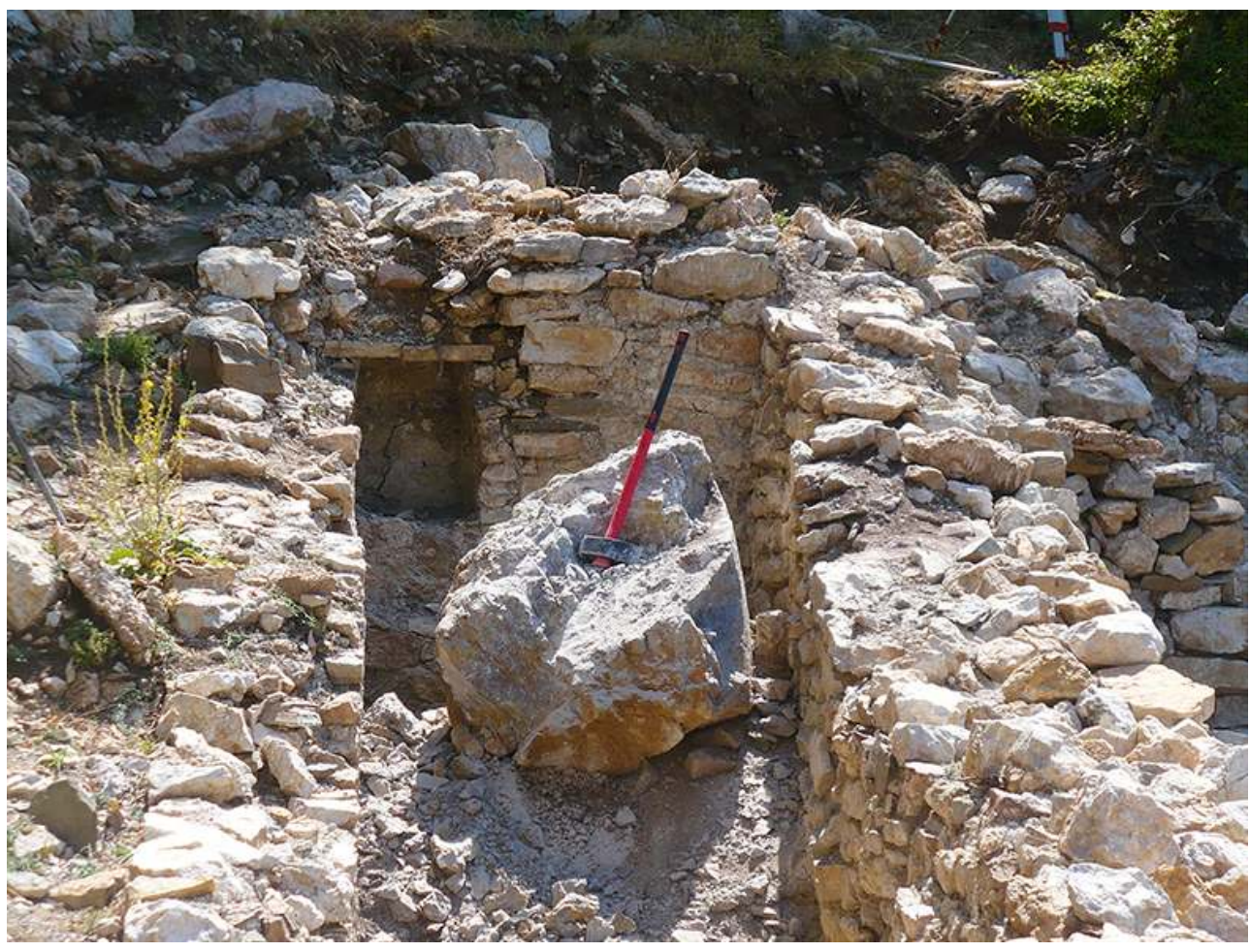

Cl. E. Nallbani.

9 L'ensemble de ces sondages a permis d'une part de mettre au jour tous les murs de l'église et de sa forme entière (voir fig. 3). Par ailleurs, la fouille des murs a conduit à la découverte des banquettes qui leur sont adossées (fig. 9); tous les murs dégagés en disposaient d'une. D'autre part, ces résultats ont soulevé de nombreuses interrogations, d'autant plus que le plan de l'église n'est pas symétrique : il s'agit notamment de valider la poursuite des banquettes contre les murs nord et sud de la nef et de comprendre leur évolution au regard de la succession des différentes baies; de mieux cerner et caractériser toutes les ouvertures. Pour chacune d'elle, déterminer une chronologie relative vis-à-vis des murs et des aménagements et des comblements internes à l'instar des marches et des banquettes. Les différences d'altitudes entre les structures perçues dans l'abside et le niveau de sol mis au jour dans le sondage 1740, laissent supposer un ensemble de marches. L'hypothèse se fonde sur la présence de la marche observée et qui plaide pour la réitération d'un tel aménagement plutôt que le recours à un pendage qui aurait été bien trop important (voir la coupe réalisée de l'intérieur de la nef : fig. 10). Une volée de marches est attendue sans, cependant, qu'il soit possible d'en préciser la localisation. 
Fig. 9 - Église, zone 1B. Banc dans l'angle nord-ouest de la nef.

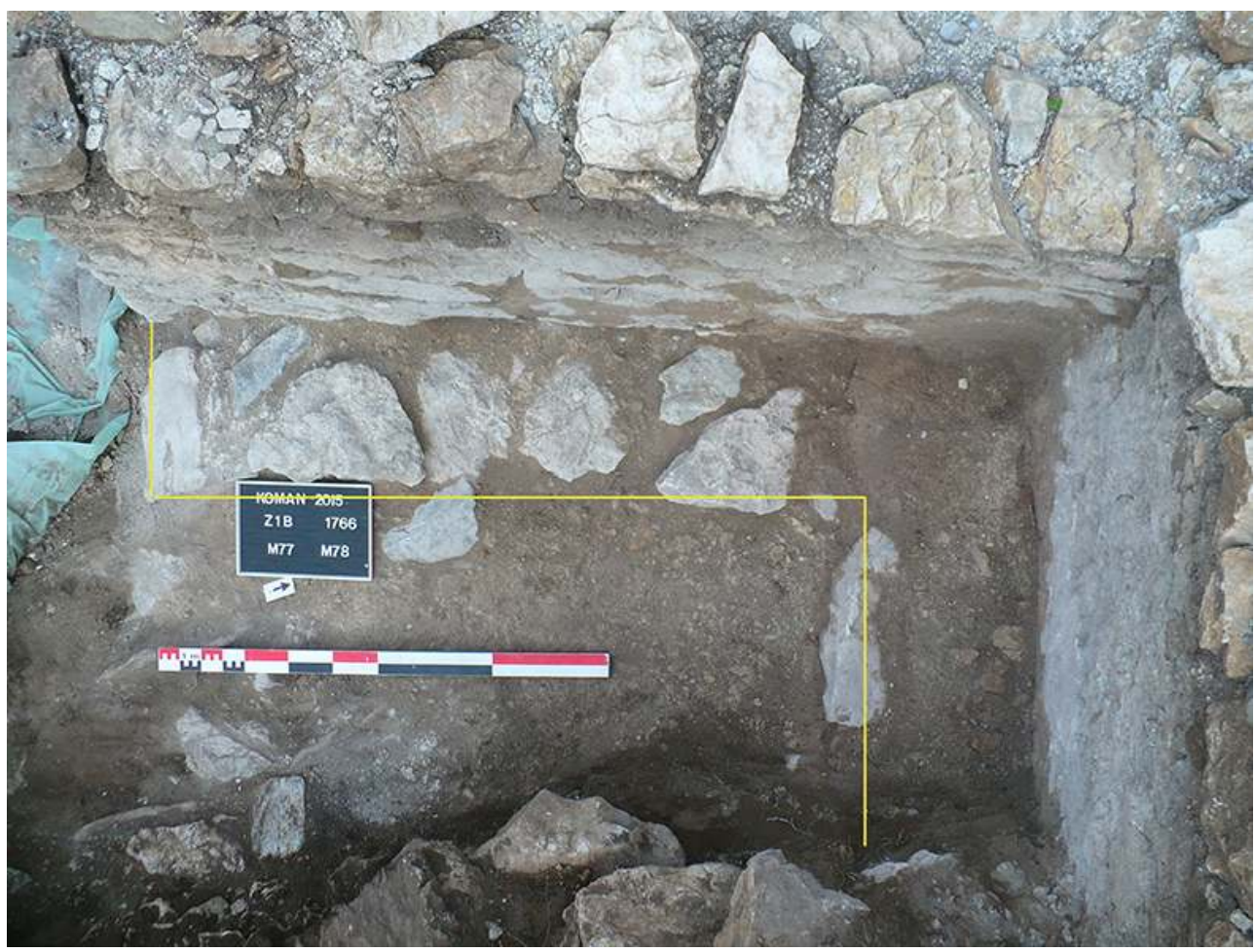

Cl. Y. Bonfand.

Fig. 10 - Église, zone 1B. Coupe transversale de la nef - M50.

Ouest
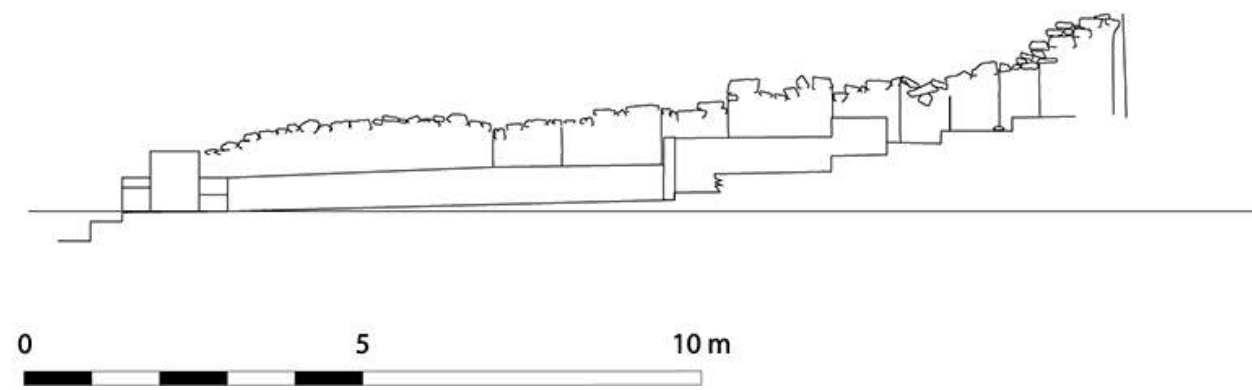

DAO Y. Bonfand, W. Boutenbat, S. Vatteoni.

\section{La fouille de la nef en 2016}

Afin de mettre au jour toute la nef de l'église, deux secteurs ont été distingués en se servant comme point de départ du sondage 1740. Au-delà d'une pure division spatiale, c'est la délimitation de deux espaces cohérents qui a été opérée avec des objectifs de fouille spécifiques qui suivent les hypothèses émises à l'issue des opérations précédentes : - mettre au jour le niveau de sol (perçu dans les sondages 1715 et 1740) sur toute la 
surface de la partie ouest de la nef ; aucune marche n'étant attendue, la problématique se focalisait sur l'aménagement des banquettes ;

- dans la partie est, l'objectif visait la jonction avec les vestiges liturgiques du chœur, plus particulièrement d'appréhender les solutions élaborées pour pallier le pendage (fig. 11) - la présence de marches supplémentaires - ainsi que de veiller à la présence du chancel.

Fig. 11 - Église, zone 1B. Coupe schématique de la berme ouest du sondage 1740 (coupe sudnord).

\section{Koman 2015}

Sondage 1740 - coupe schématique sud-nord Berme ouest

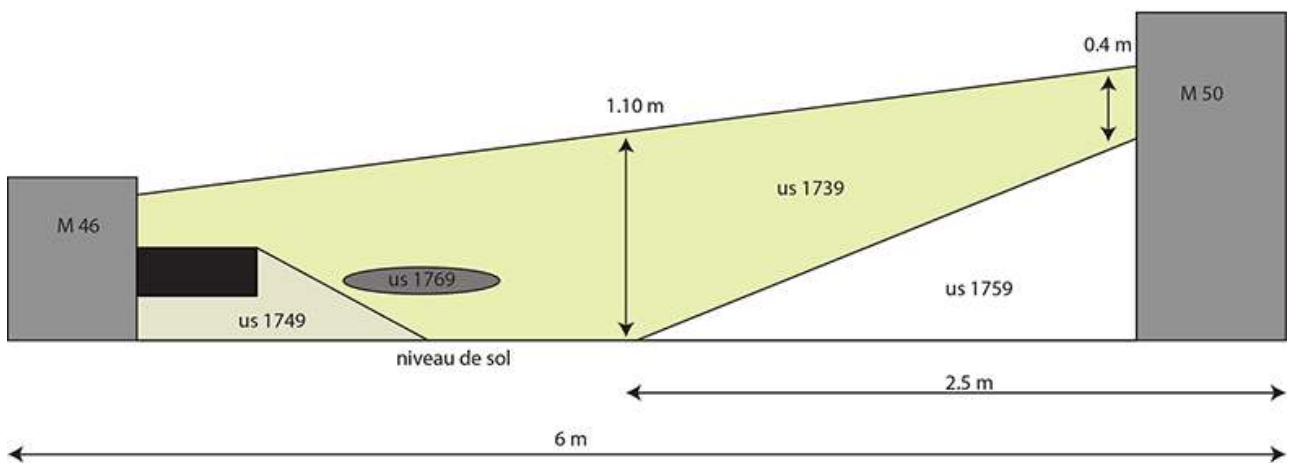

DAO Y. Bonfand.

\section{Les niveaux de destruction}

11 En effet sur l'ensemble de la nef, la superposition des niveaux archéologiques se présentait assez simplement. La fouille de ces niveaux dans le cadre du sondage 1740 a permis de montrer qu'il s'agissait de niveaux de destruction de l'église. L'US 1739, comportait un mélange de la roche provenant de la falaise immédiatement adjacente (voir fig. 4 et 9) et une grande quantité de pierres ayant servi à la construction de l'église. Certaines d'entre elles disposaient encore de traces de mortier, qui se font très denses près du niveau de sol. Le peu de matériel, essentiellement métallique, est visiblement résiduel : anneaux, boucle de ceinture, pointe de flèche. Au contact des niveaux des sols et des marches de l'église, des éléments taillés en tuf sont apparus.

Deux niveaux de destruction (US 1749 et 1759) se distinguent nettement dans la nef. Il s'agirait de la désagrégation progressive des murs de l'église, où la destruction mêle plusieurs couches d'enduits qui se sont succédé sur les murs et les banquettes laissant, parfois, apparaître des motifs peints (US $1810 ; 1812 ; 1826$; 1830) (fig. 12) et de nombreux éléments en tuf. L'église a été longtemps abandonnée avant sa destruction qui paraît naturelle. 
Fig. 12 - Église, zone 1B. Pilier de terre, pierres et mortier venant maintenir le mur M50.

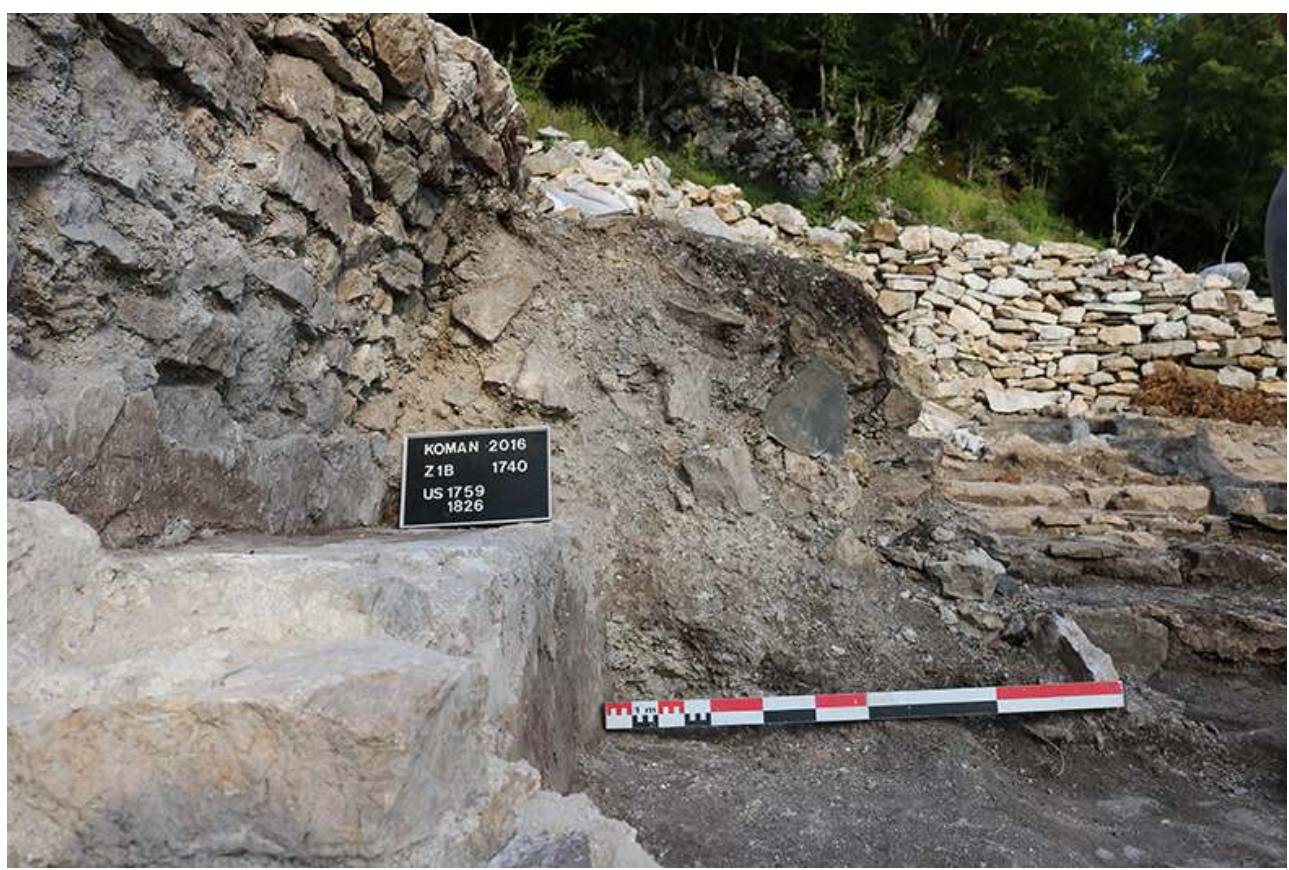

Cl. Y. Bonfand

De nombreuses dalles à plat ou mêlées aux gravats appartiennent aux éléments de toiture détruits, essentiellement disposés à plat (fig. 13), comme toute la partie du sanctuaire fouillée en 2014. Cependant, après observation des méthodes de construction des murs, des banquettes et des marches, il s'avère que ces matériaux constamment utilisés aussi pour les sépultures étaient parfois d'utilité en qualité de calage ou remplissage d'aménagements.

Par ailleurs, cinq clous mis au jour dans les niveaux de destruction des murs attestent cependant de la présence d'une charpente en bois, quoi qu'ils se révèlent particulièrement peu nombreux. 
Fig. 13 - Éléments de toiture effondrés sur la banquette (US 1845).

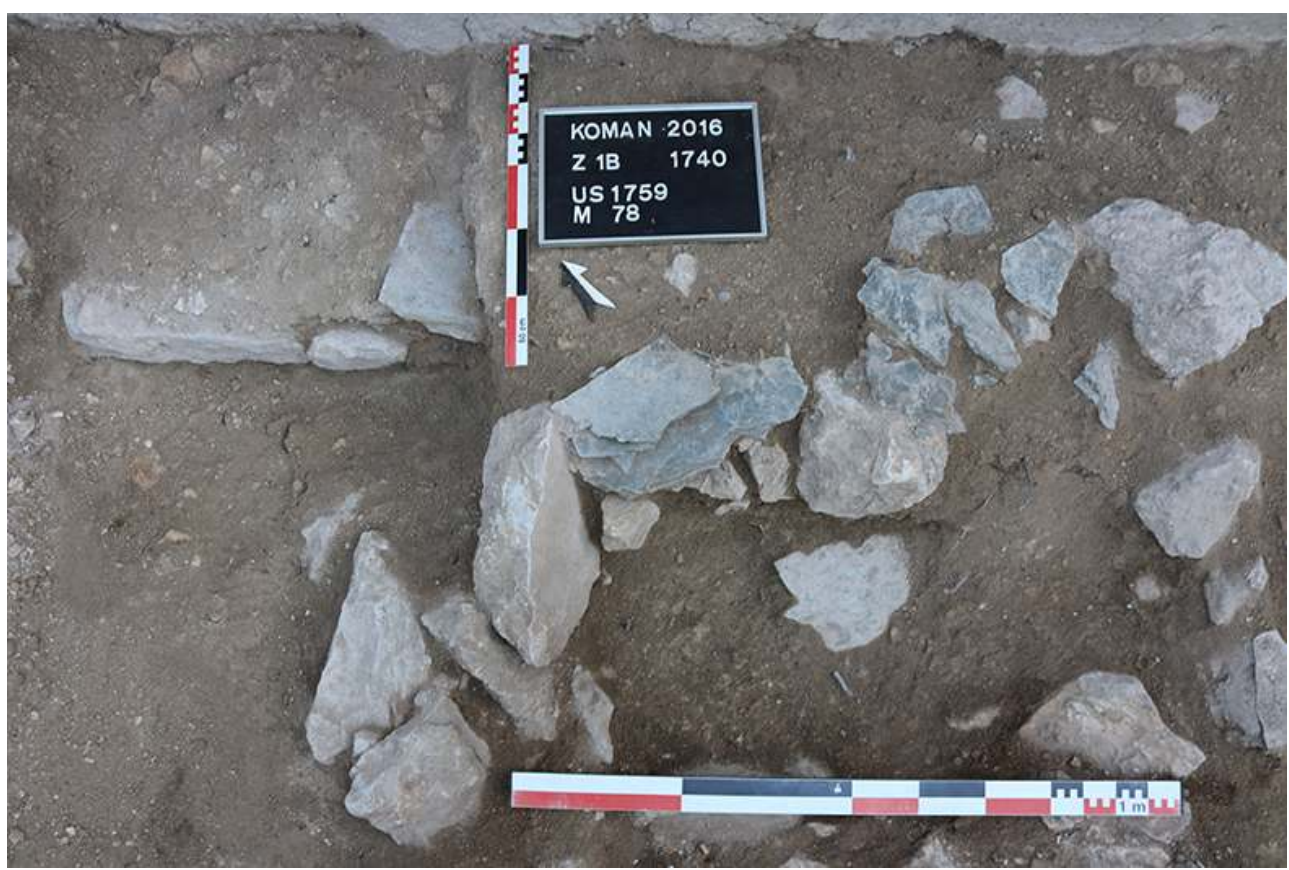

Cl. Y. Bonfand.

\section{Aménagements intérieurs de la nef (fig. 48)}

14 Une rationalisation des désignations des murs, réalisées lors des précédentes campagnes s'est avérée, de fait, nécessaire en 2016.

\section{Les murs}

De façon homogène, les murs sont constitués de pierres grossièrement équarries liées au mortier (fig. 14) et recouverts d'enduits, très partiellement conservés (fig. 15). La fouille a permis de mettre en évidence quelques niveaux de fondation, reposant sur le rocher naturel, dont l'apparence se distingue par un bourrelet de mortier débordant des maçonneries. Les pierres mises en œuvre dans l'élévation sont de dimensions et de formes très variées. 
Fig. 14 - Église, zone 1B. Bouchage d'une baie du mur 50 (vue depuis le Nord).

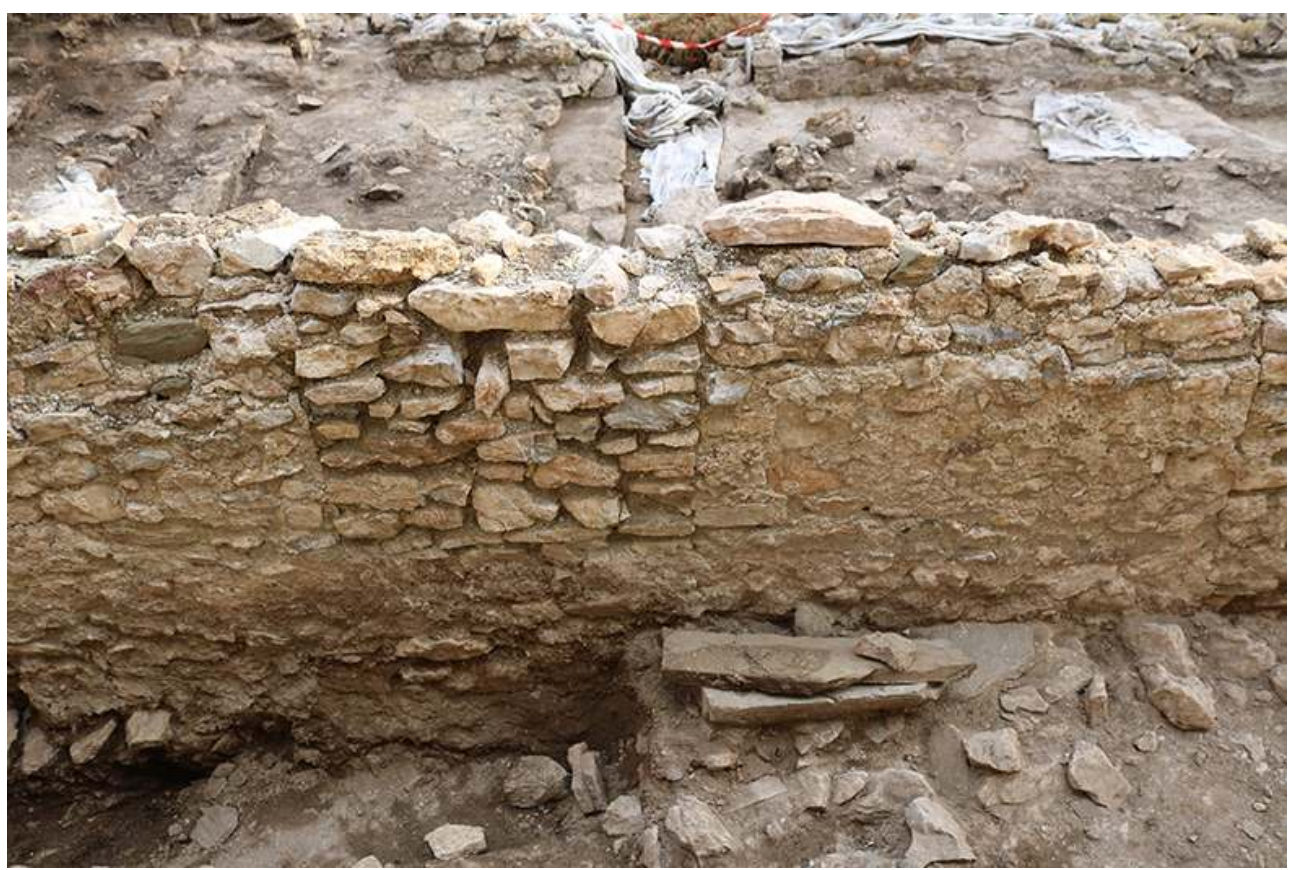

Cl. E. Nallbani.

Fig. 15 - Église, zone 1B. Banquette 1846 et mur M50, avec traces d'enduits.

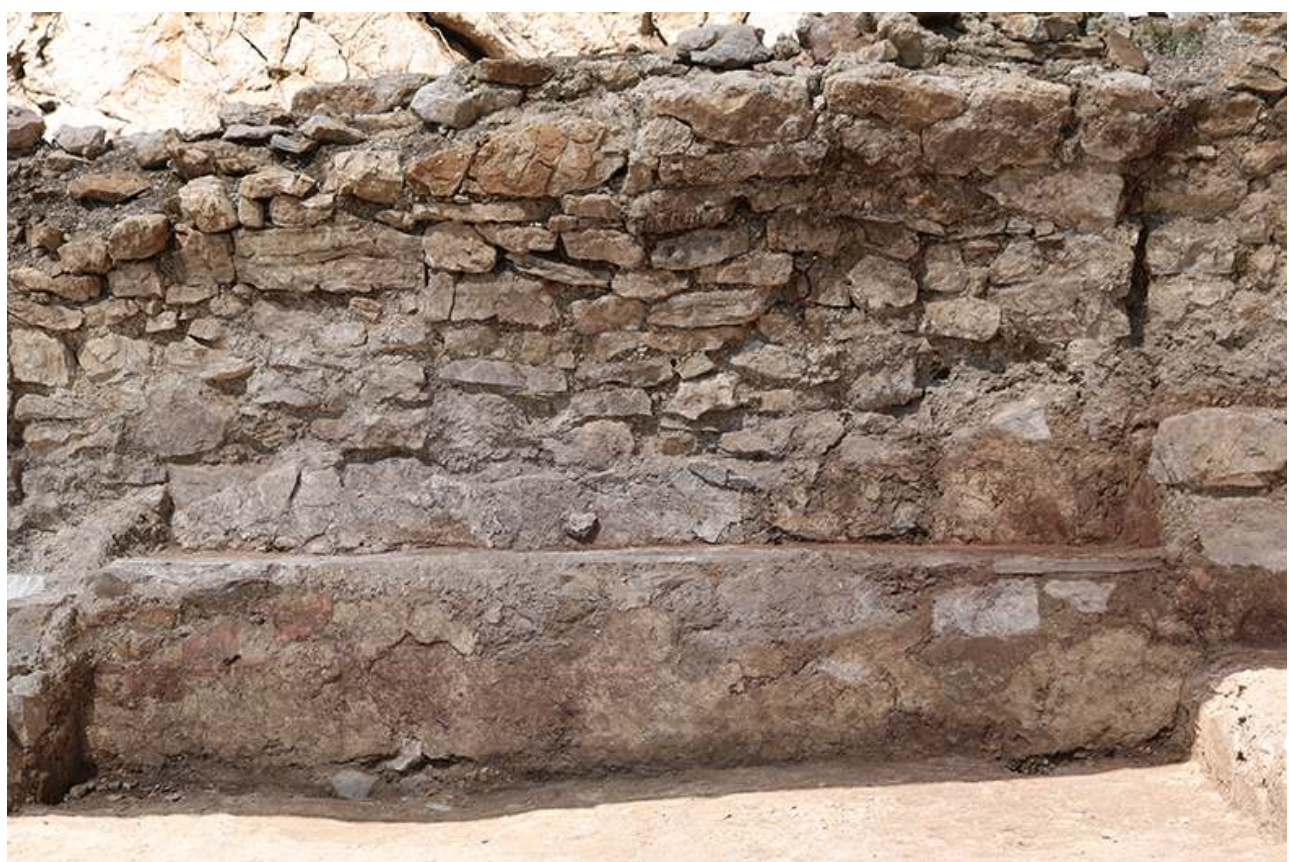

Cl. Y. Bonfand.

\section{Les baies}

L'église présente une dissymétrie à plusieurs égards: d'abord la présence d'un seul collatéral - au Nord, attenant à la falaise - ensuite les murs qui ne suivent pas 
véritablement des axes rectilignes, enfin la répartition des baies ne présente aucune similarité entre les deux murs de la nef.

\section{Le mur sud, M46}

Deux ouvertures ont été perçues dans le mur sud (US 1783 et 1881), au niveau desquelles les banquettes sont interrompues, attestant qu'un passage y était possible. Par ailleurs, elles précèdent toutes deux une marche de la nef. L'une, à l'Ouest, mesure près de $1,20 \mathrm{~m}$ de longueur (fig. 7) quand l'autre, à l'Est, est plus petite et de forme légèrement trapézoïdale (fig. 16). Elle s'ouvre sur la nef, le côté droit s'aligne avec la marche 1817 et fonctionne avec l'aménagement 1870 et la banquette 1850. Quant aux fenêtres, l'état de conservation de l'élévation ne permet pas de considérer leur existence ou d'en suspecter la localisation.

Fig. 16 - Église, zone 1B. Baie est du mur sud M46 - US 1881.

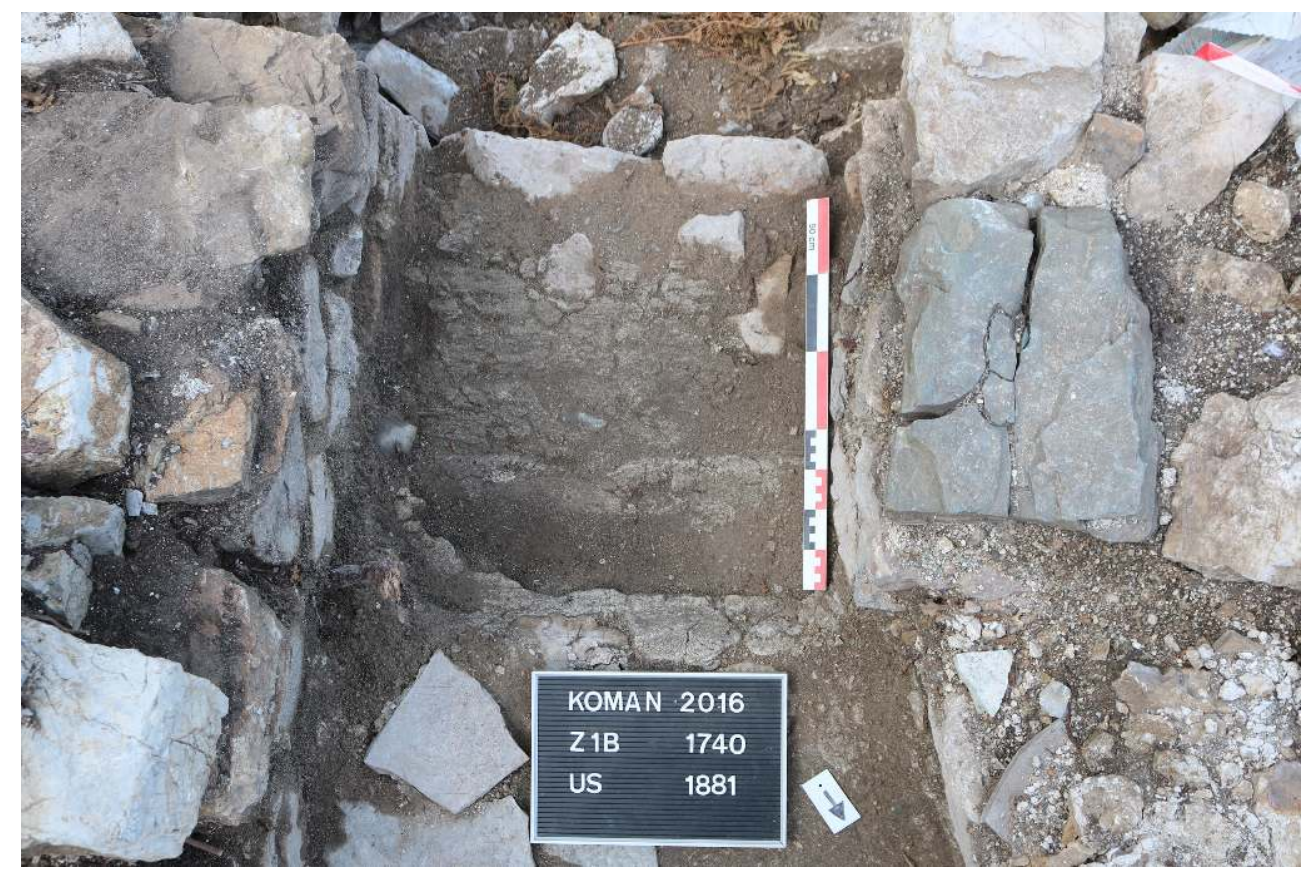

Cl. Y. Bonfand

Le mur nord, M50 (fig. 10 ; fig. 17 ; fig. 48) 
Fig. 17 - Église, zone 1B. Coupe Est-Ouest du mur M50 - intérieur du collatéral.

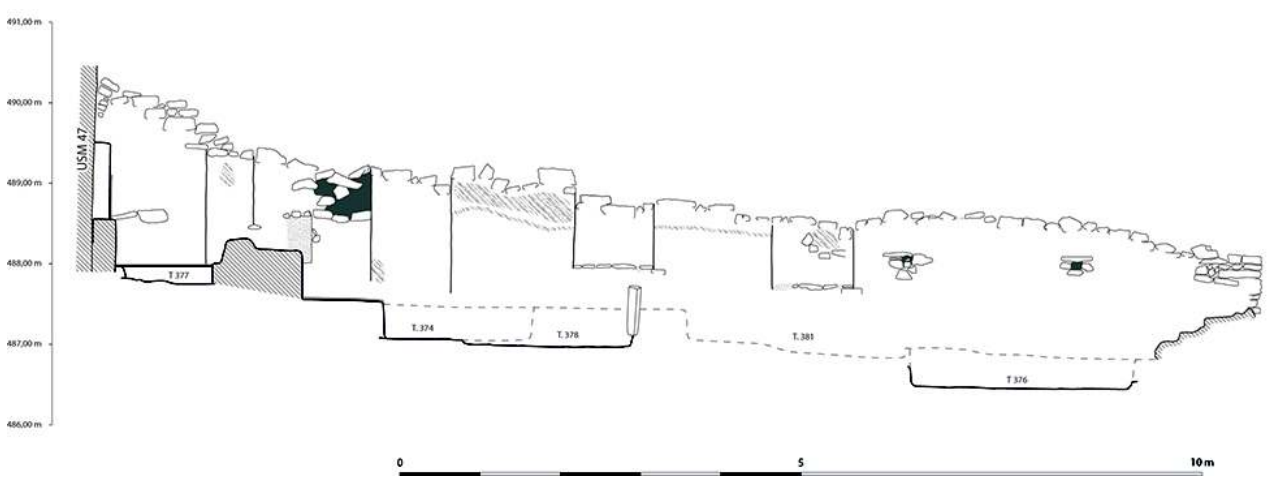

DAO S. Vatteoni.

Au mur aveugle à l'Ouest, de près de $5 \mathrm{~m}$, succède une alternance de deux baies d'une longueur de $1 \mathrm{~m}$ qu'entrecroisent des piliers longs de 1,70 m. Ces baies ne permettaient pas la circulation (fig. 15). Une série de coups de sabre ont invité à voir dans la suite de ce mur une succession de bouchages dont la mise en œuvre est longtemps demeurée énigmatique (fig. 18) :

A : Second pilier de 1,70 m. Lié au mortier ; B : Ancienne baie bouchée d'environ $1 \mathrm{~m}$; C : Un pilier est attendu ici. Toutefois, l'élévation est bien trop endommagée pour y voir une structure architecturale ; D : Baie? La base est recouverte d'un enduit peint figuratif ( fig. 19). Par ailleurs, le bouchage hypothétique est lié à $\mathrm{E}$ par une base commune qui apparait sur le parement du collatéral (fig. 20) ; E : Pilier ? ; F : Lié au mur par un mortier, cet espace était ouvert comment l'attestent les vestiges mis au jour dans le collatéral ( fig. 21).

Au regard de ces éléments, il semblerait donc que la succession soit la suivante : A : pilier/ $\mathbf{B}$ et $\mathbf{C}$ : bouchages en deux temps/ $\mathbf{D}$ et $\mathbf{E}$ : reconstruction de deux piliers/ $\mathbf{F}:$ bouchage.

Fig. 18 - Église, zone 1B. Piliers et bouchages - M50.

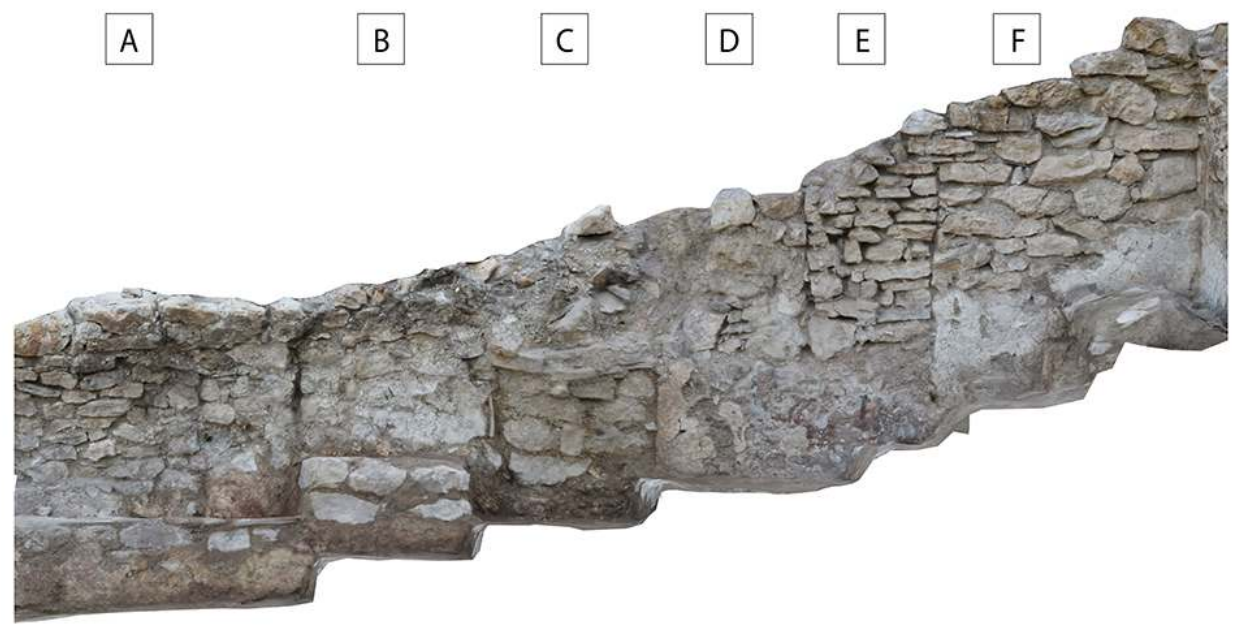

Cl. Y. Bonfand. 
Fig. 19 - Église, zone 1B. Scène figurative peinte.

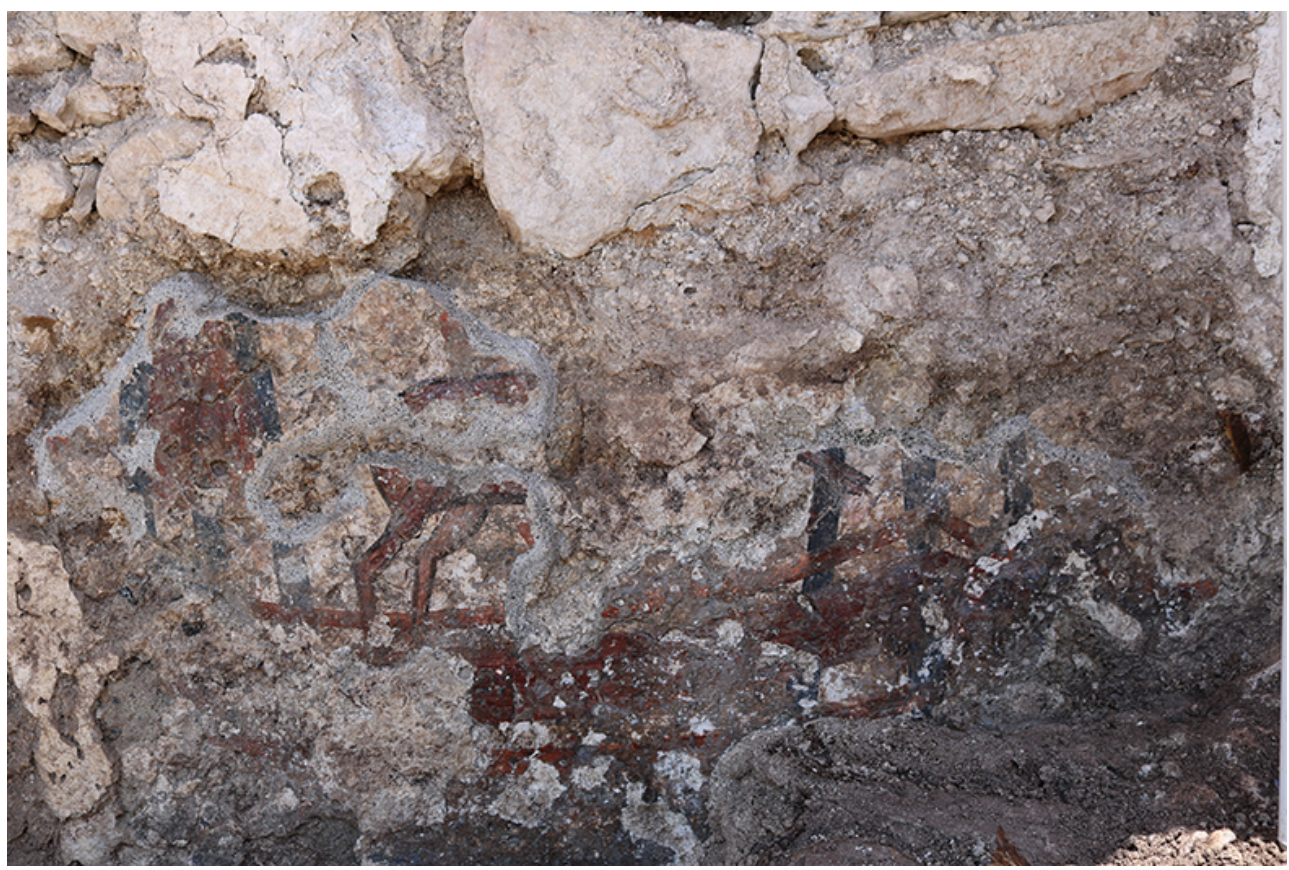

Cl. E. Nallbani.

Fig. 20 - Église, zone 1B. Soubassements des bouchages du mur M50 (parement nord, dans le collatéral).

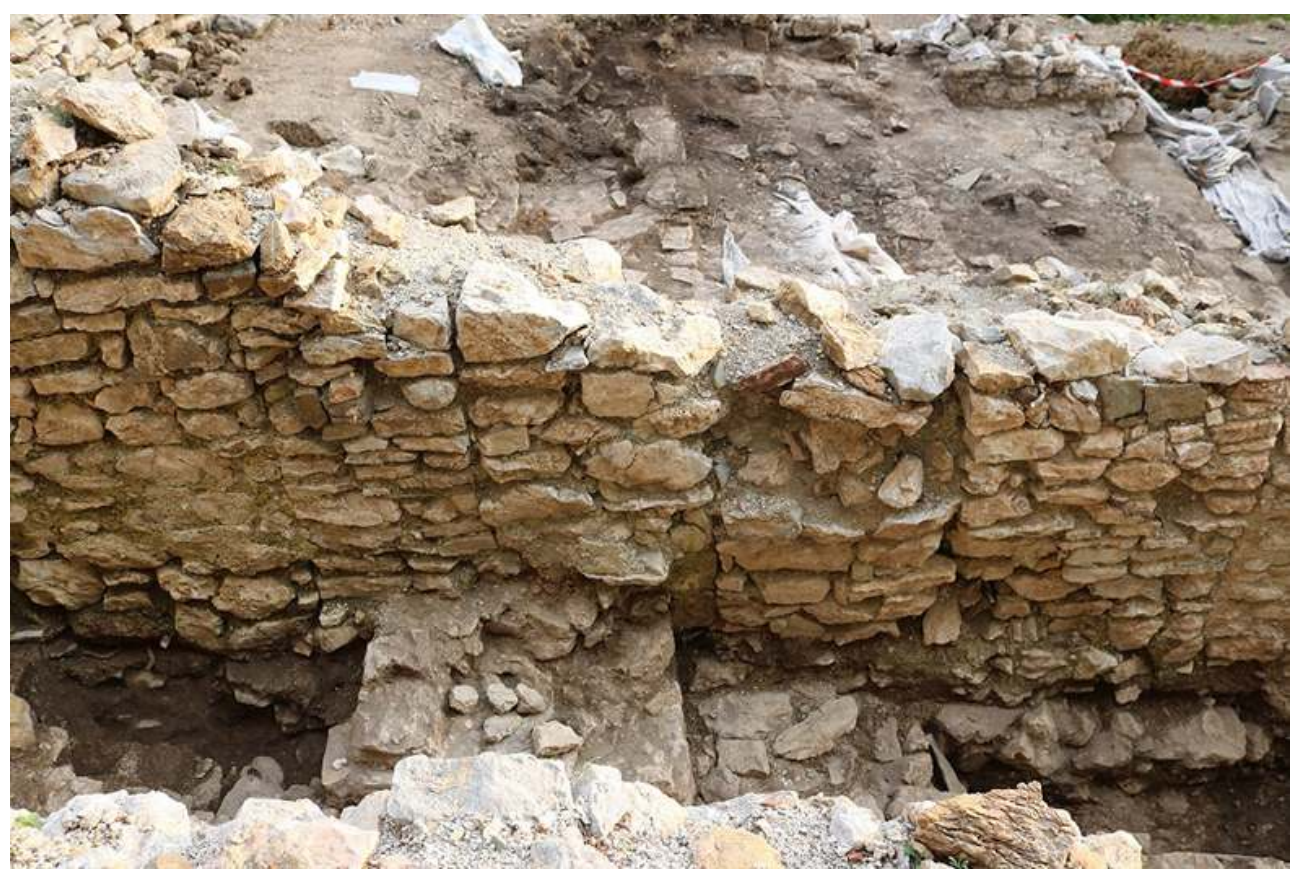

Cl. E. Nallbani. 
Fig. 21 - Église, zone 1B. Bases (fondations ?) d'un aménagement du collatéral qui communique avec la nef (mur M50 à droite).

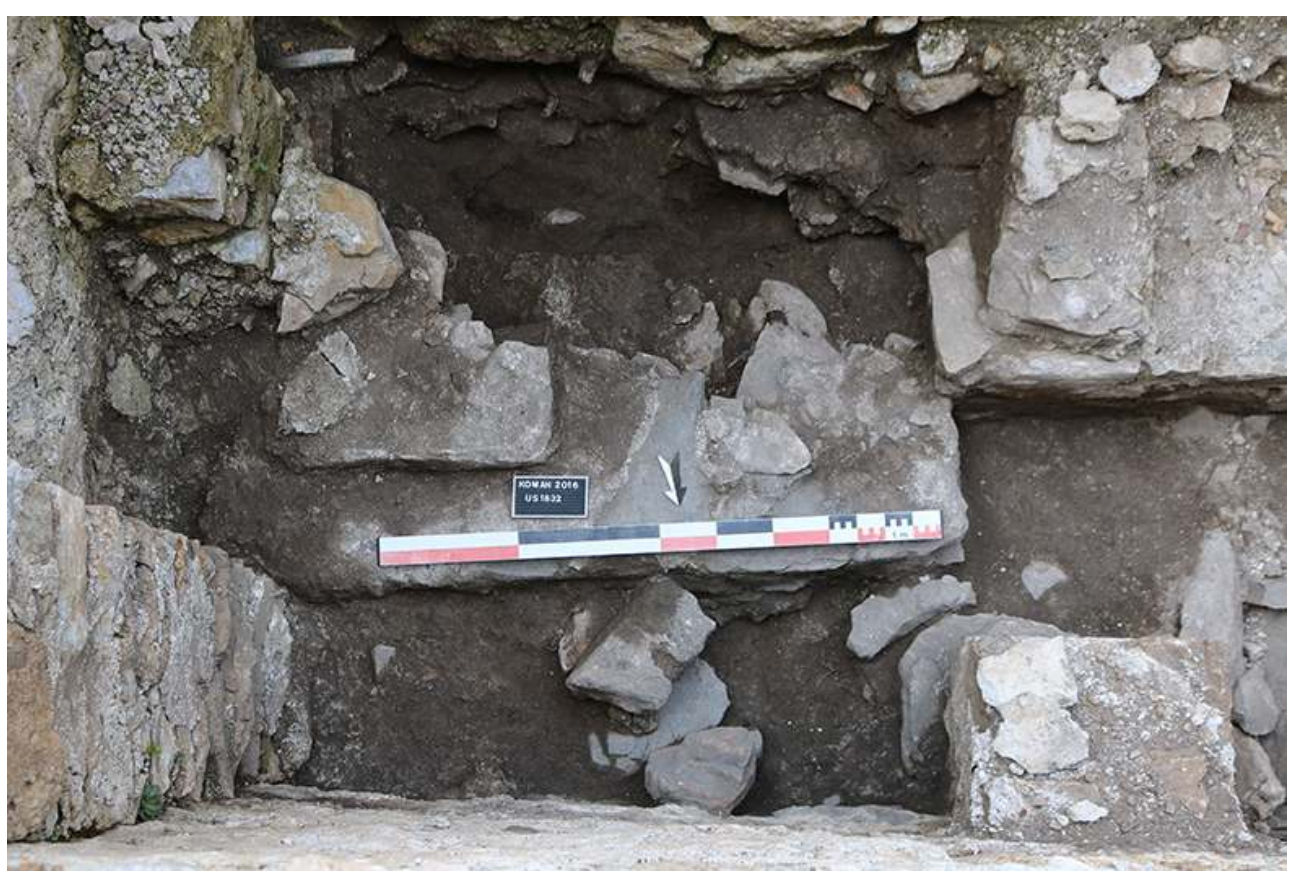

Cl. Y. Bonfand.

\section{La façade principale (M61 et M79)}

Les deux murs M61 et M79 délimitent l'accès principal de l'église à l'Ouest. D'une ouverture d'environ $1,50 \mathrm{~m}$, le seuil est attesté par un niveau de mortier (fig. 22). Cependant, un bourrelet de mortier proéminent contre le piédroit et dans l'alignement du parement nord laisse penser qu'il existait une structure de seuil (une dalle ?) que l'on appréhende en négatif (fig. 23). Le mur M79 est désaxé, ce qui s'explique certainement par la violence du choc subi lors de l'éboulement de la pierre (fig. 4). 
Fig. 22 - Église, zone 1B. Emmarchement de la façade principale.

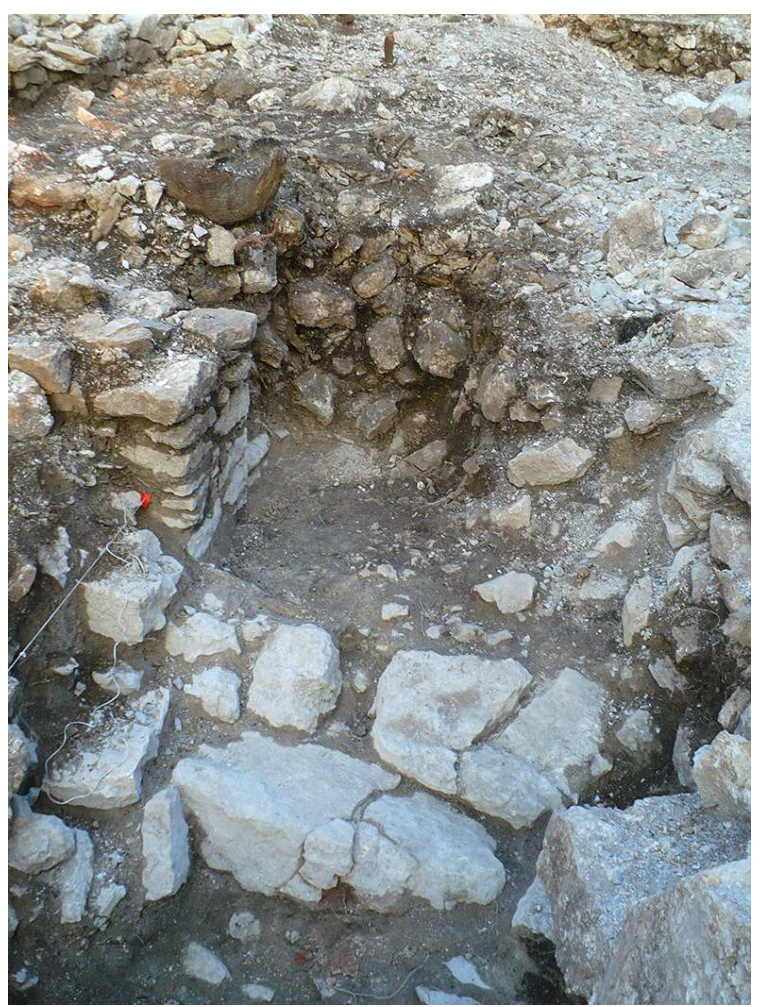

Cl. Y. Bonfand.

Fig. 23 - Église, zone 1B. Seuil d'entrée avec bourrelet de mortier.

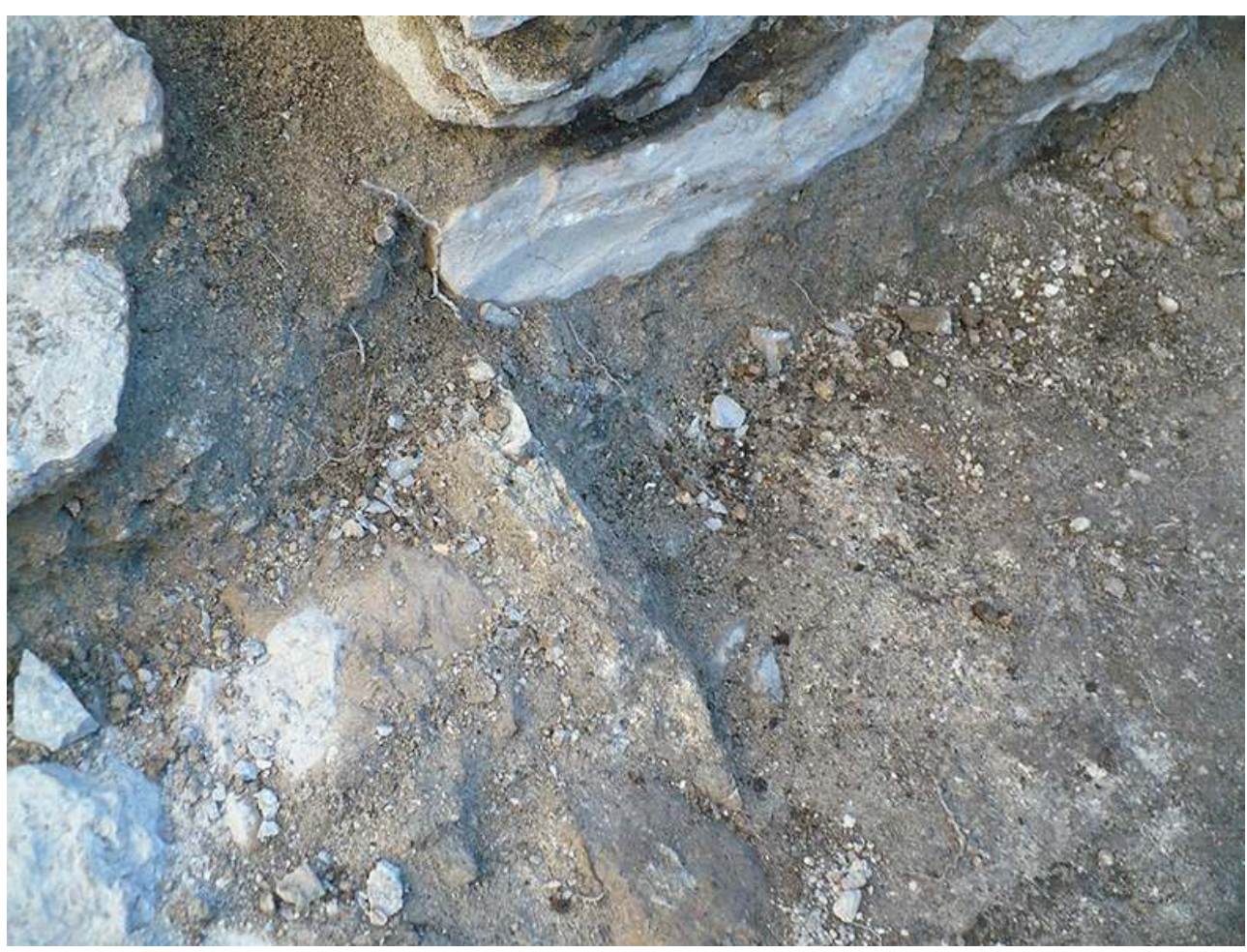

Cl. Y. Bonfand. 


\section{Les banquettes (fig. 48, fig. 24)}

Fig. 24 - Église, zone 1B. Banquettes $1845 ; 1846 ; 1891$.

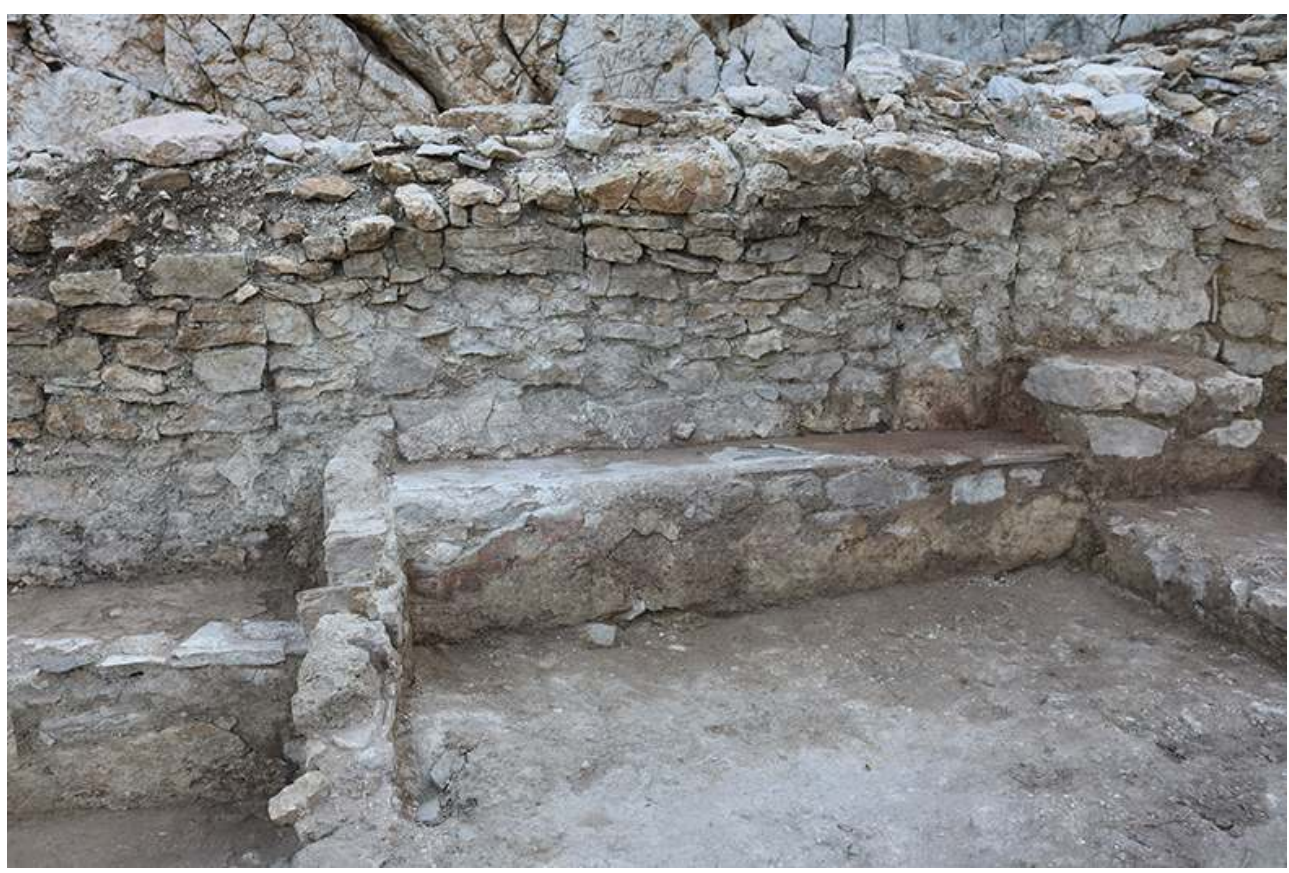

Cl. Y. Bonfand.

Au total, ce sont neuf banquettes qui ont été distinguées (1843 à l'extérieur - fig. 5 ; 1844, 1845,1846 et 1891 pour la partie nord de la nef [fig. 24] ; 1847, 1848, 1849 [fig. 9] et 1850 pour la partie sud). Leurs dimensions varient entre 0,40-0,50 m de large, pour 0,30-0,45 m de haut et de longueur très variable. Bien qu'elles présentent des états de conservation variables, elles sont toutes construites selon un même principe de pierres assisées recouvertes dans leur dernier état d'une couche d'enduit, qui se poursuit des murs jusqu'au sol. La présence d'une banquette contre le parement extérieur du mur M79 demeure hypothétique. 
Fig. 25 - Église, zone 1B. Enduit peint de la banquette 1846.

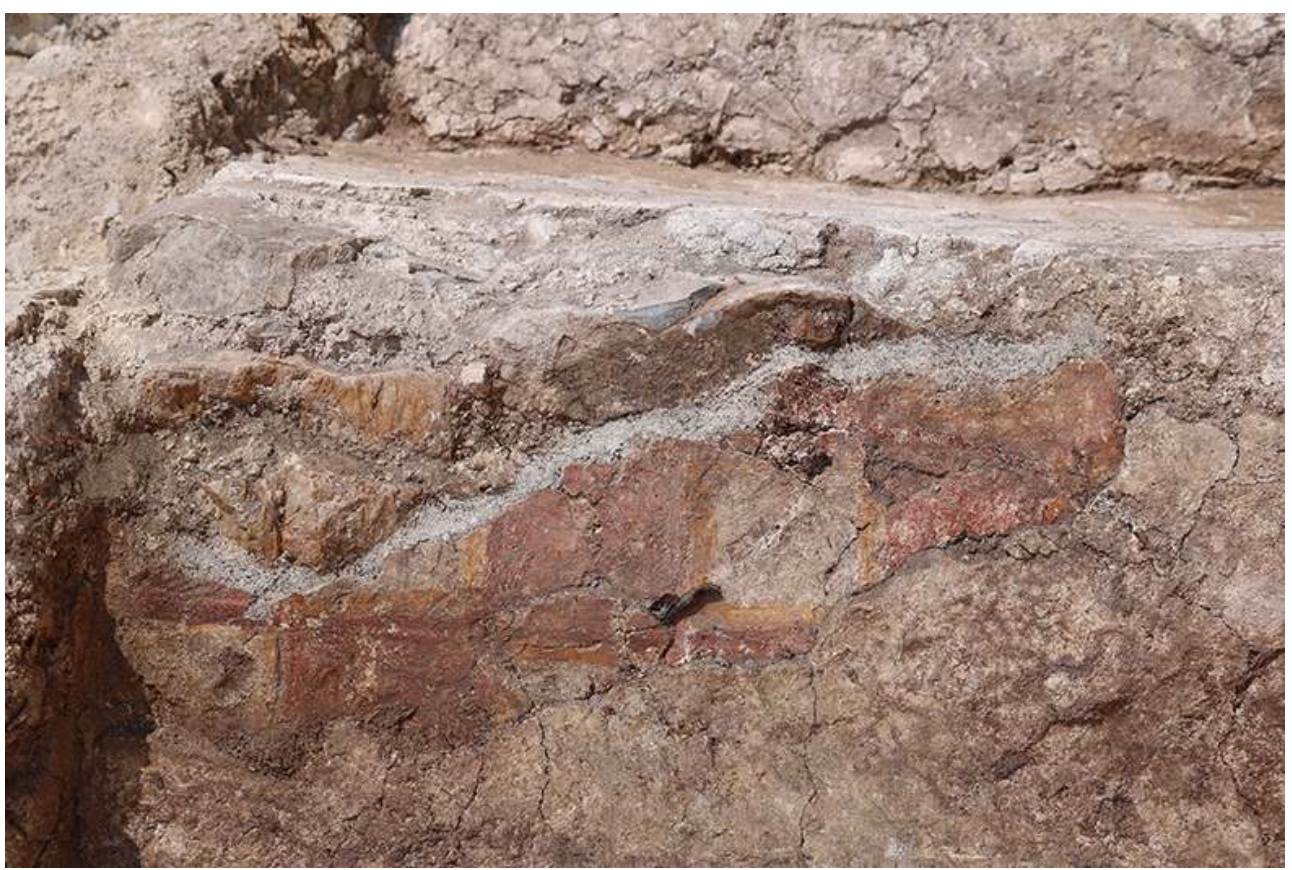

Cl. Y. Bonfand.

21 Il convient de remarquer que tous les éléments de décor - les enduits peints (fig. 39-40) ne peuvent catégoriquement provenir des banquettes. La mise au jour d'un décor en place (disposition en quinconce de rectangles blancs bordés d'un cadre jaune sur fond rouge) dégagé sur une fenêtre de $0,45 \times 0,20 \mathrm{~m}$ (US 1825) sous la couche de mortier claire (US 1824) qui venait le recouvrir (US 1825, fig. 26) atteste que les banquettes étaient, elles aussi, décorées. La découverte d'enduits sur la banquette 1846 démontre que les murs l'étaient eux aussi. De fait, et en l'absence d'étude stylistique et comparative, il ne paraît pas possible pour le moment de rattacher les enduits aux murs ou aux banquettes. 
Fig. 26 - Église, zone 1B. Vue sur la nef depuis l'Ouest.

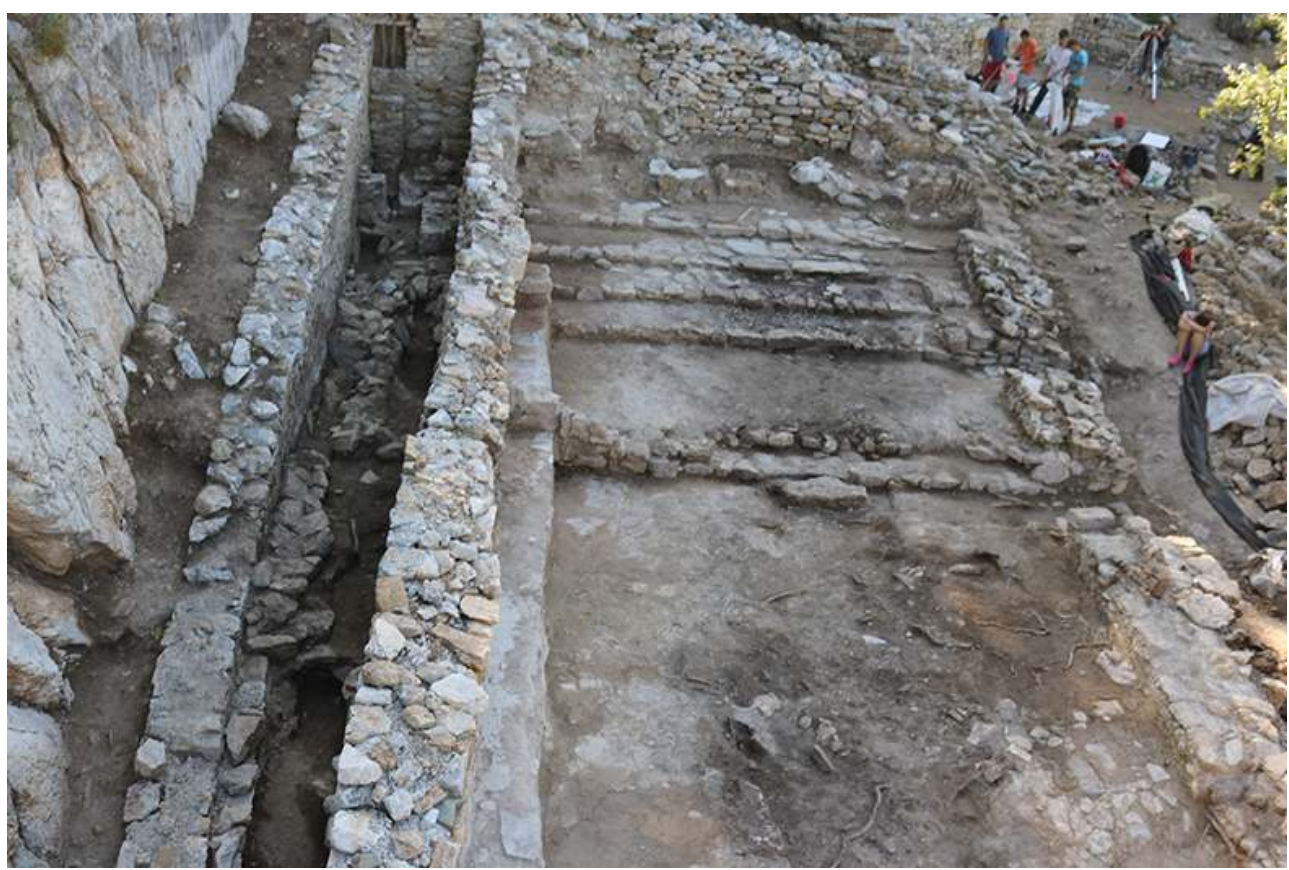

Cl. Y. Bonfand.

\section{Les marches}

Une première marche centrale dans la nef a été mise au jour lors à la campagne précédente (US 1781, fig. 7). Elle fonctionne avec la structure en tuf 1839 et la baie ouest du mur sud M46. En 2016, un ensemble de marches attendues a été mis au jour : une volée de quatre (d'Est en Ouest : $1817 ; 1818 ; 1837 ; 1838$ ). De façon générale, les marches ont conservé leur couverture en mortier sur leurs parties les plus proches des murs latéraux de la nef. Elles sont de 0,17 à $0,20 \mathrm{~m}$ de hauteur et constituées de grosses pierres assisées derrière lesquelles l'on a procédé à un comblement de dalles de schiste liées à la terre ( fig. 10 ; fig. 26-29). 
Fig. 27 - Église, zone 1B. Vue sur la nef depuis le Sud-est.

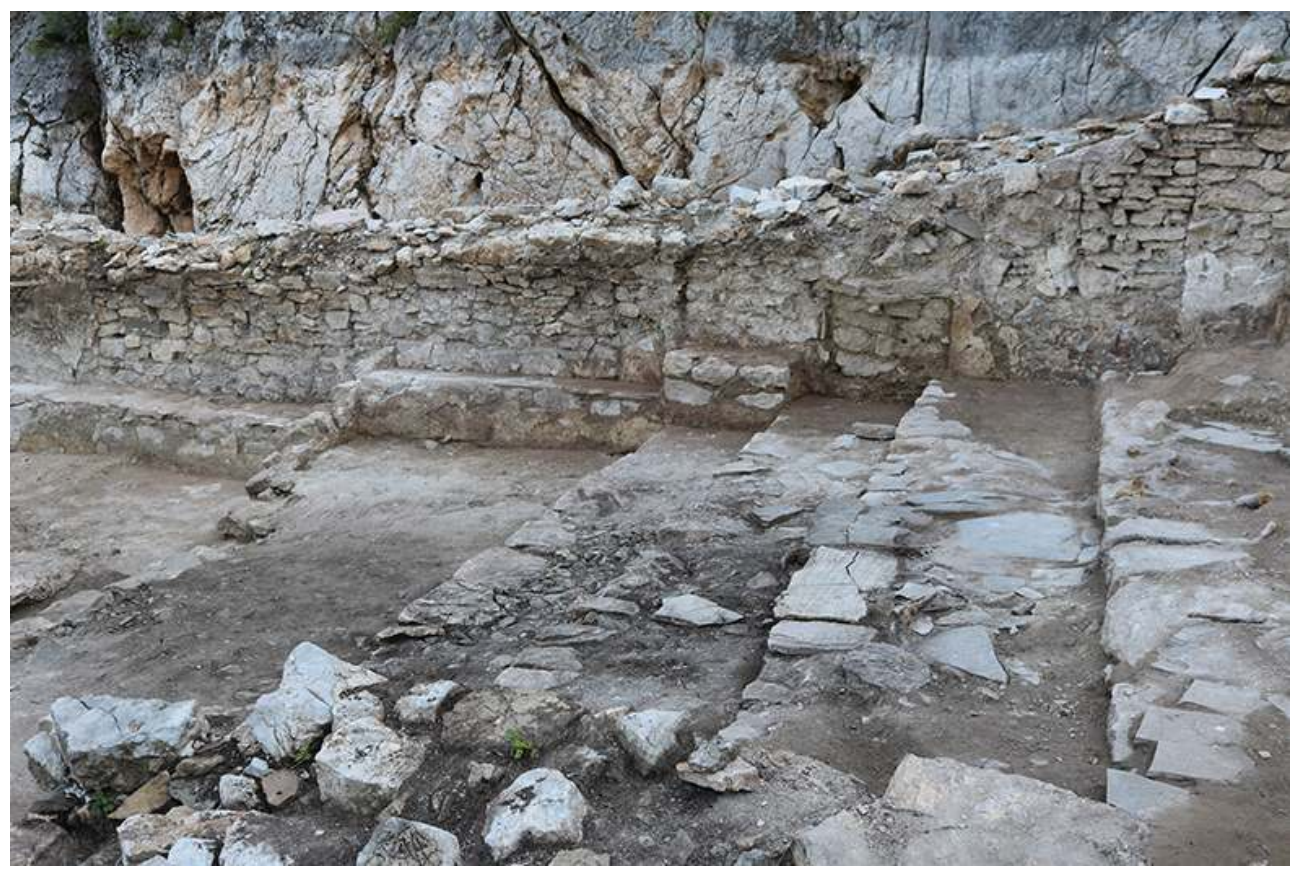

Cl. E. Nallbani.

Fig. 28 - Église, zone 1B. Marches 1837 et 1838 avec mortier (US 1892).

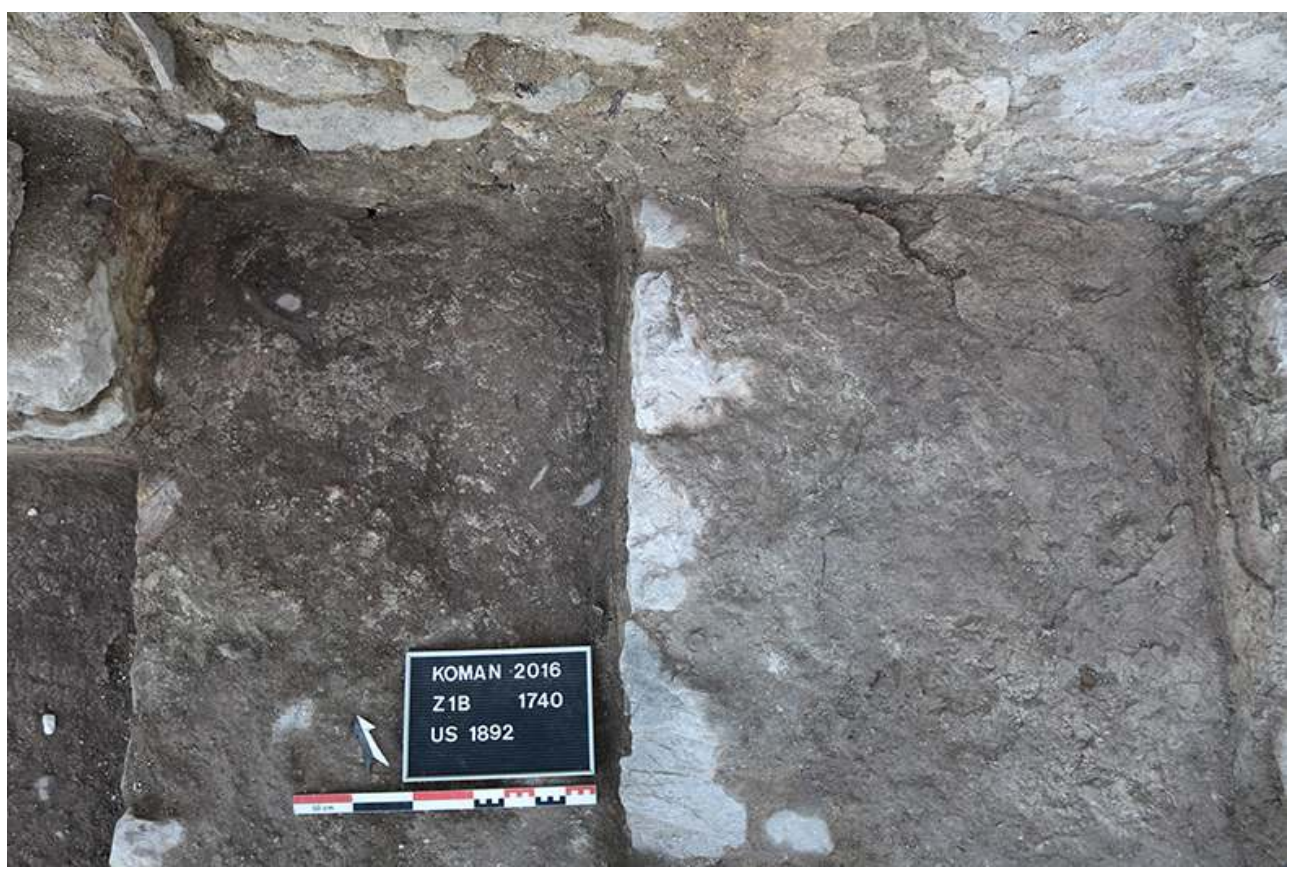

Cl. Y. Bonfand. 
Fig. 29 - Église, zone 1B. Marche 1838.

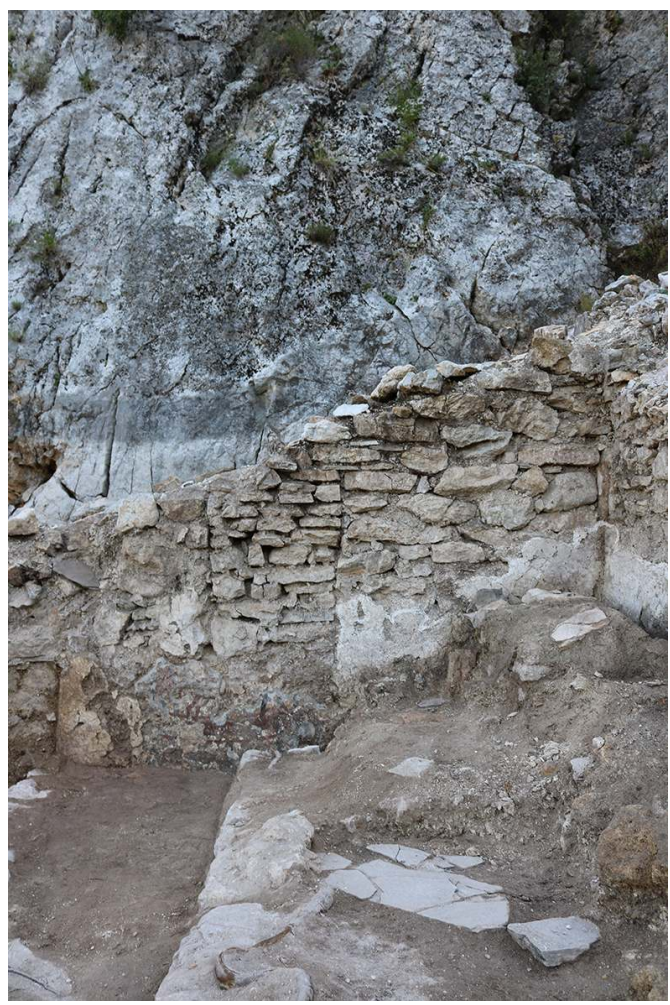

Cl. Y. Bonfand.

Les marches 1817 et 1818 sont rehaussées chacune sur leur partie sud d'un aménagement jointif aux marches, contre la banquette 1850 . Il s'agit des structures 1870 (0,75 m de long, $0,70 \mathrm{~m}$ de large, $0,20 \mathrm{~m}$ de hauteur) et 1871 (0,80 $\mathrm{m}$ de long, 0,50 $\mathrm{m}$ de large, 0,15 $\mathrm{m}$ de haut) (fig. 30-31). Si leur emploi demeure mystérieux, elles fonctionnent en lien avec la banquette 1850 , créant un espace qui semble soustraire cette dernière de la circulation de la nef. 
Fig. 30 - Église, zone 1B. Aménagements sud $(1870,1871)$ auprès de la marche 1817 et banquette 1850 .

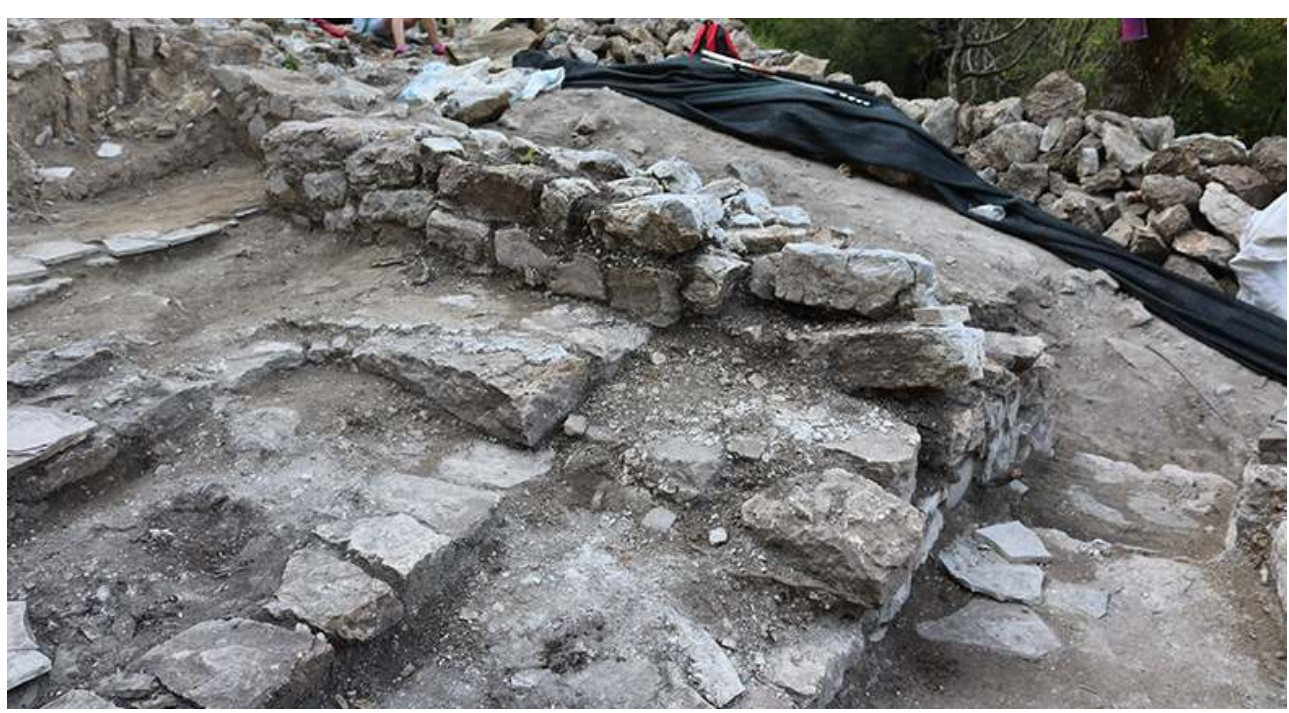

Cl. Y. Bonfand

Fig. 31 - Église, zone 1B. Aménagement sud (1871) auprès de la marche 1818 et banquette 1850.

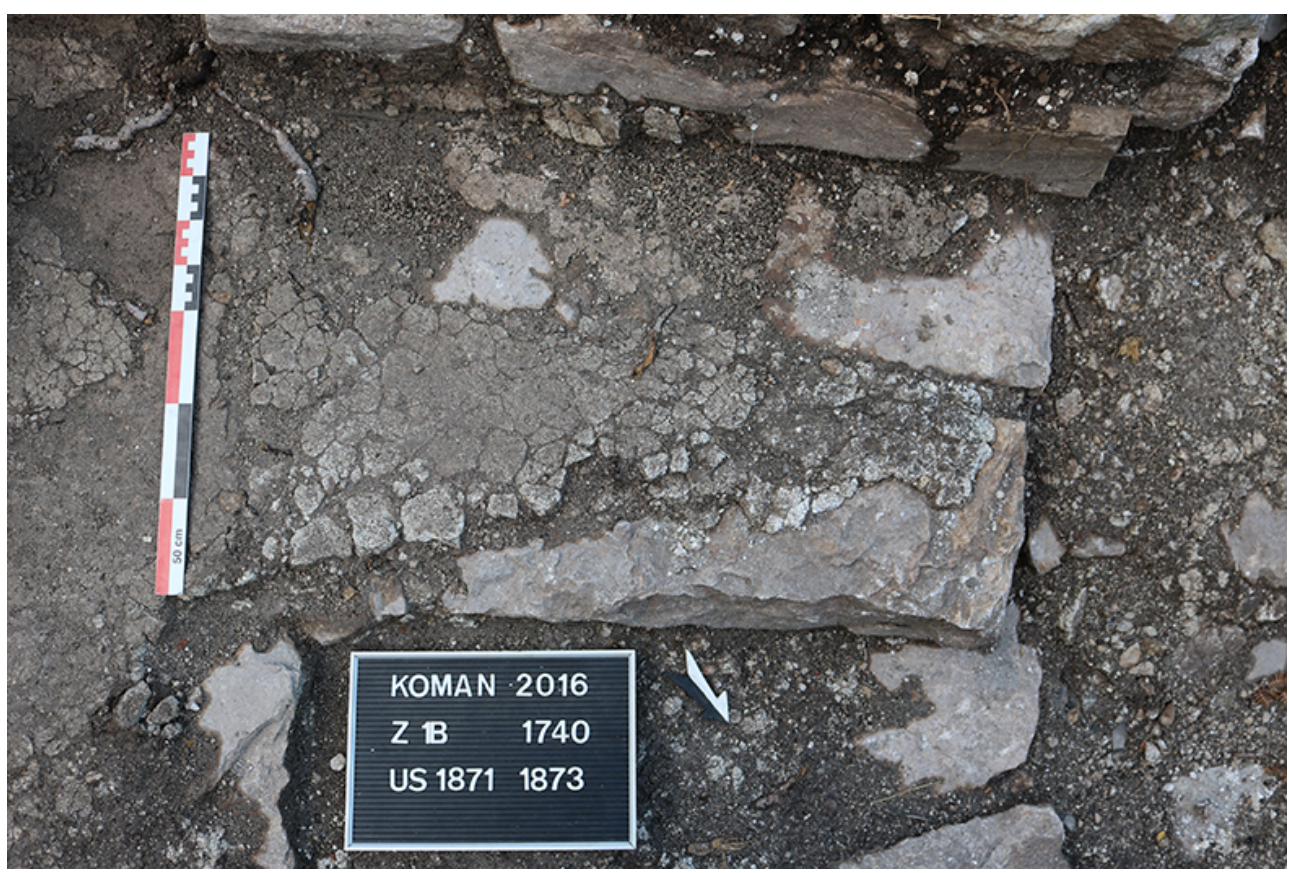

Cl. Y. Bonfand.

\section{La deuxième marche}

24 La jonction entre les niveaux de la banquette 1846, la première marche 1781 et le niveau associé à la baie 1881 demeure problématique. Alors qu'une "deuxième marche » était attendue entre les marches 1781 et 1817 afin de maintenir la montée progressive des niveaux et conserver une relative régularité entre les espacements, la fouille n'a pas permis de comprendre la relation des vestiges dans cet espace. Bien au contraire, ce sont 
deux niveaux de sol qui ont été attestés alors qu'aucune structure permettant de passer de l'un à l'autre n'a été mise au jour ou perçue.

Le niveau de la marche est attesté par sa couverture en mortier assez bien conservée (fig. 7).

Les niveaux de sol associés aux aménagements de la baie sud-est 1881 (fig. 16) et de la banquette 1846 (fig. 24 ; fig. 27) ne souffrent aucune contradiction.

\section{La structure en tuf 1839}

Entre les banquettes 1845 et 1846, un aménagement essentiellement composé de tuf vient s'appuyer contre le mur M50 (fig. 32-33). Aligné avec la marche 1781, il se suit sur une longueur de 1,45 m environ. Conservé sur une hauteur de $0,85 \mathrm{~m}$ au plus haut, il est réduit à $0,30 \mathrm{~m}$ dans sa partie sud. Déversée vers l'Ouest, la structure a visiblement et sans surprise subit un choc à l'origine de sa destruction. Aucun indice n'a permis d'en définir la hauteur originelle. Son épaisseur constante de $0,20 \mathrm{~m}$ en fait une délimitation qui pourrait se rapporter à un parapet venant solenniser l'espace de la banquette 1846 par ailleurs très richement décoré d'enduits peints. La structure doit être associée aux nombreux éléments de tuf mis au jour dans les US de destruction 1759 et 1749 qui se suivent sur toute la largeur de la nef. Il serait ainsi envisageable de l'identifier à la barrière de chancel traversant perpendiculairement la nef, afin de souligner le caractère sacré de l'espace, les escaliers conduisant vers les aménagements liturgiques et le synthronon.

Fig. 32 - Église, zone 1B. Aménagement en tuf, chancel (US 1839).

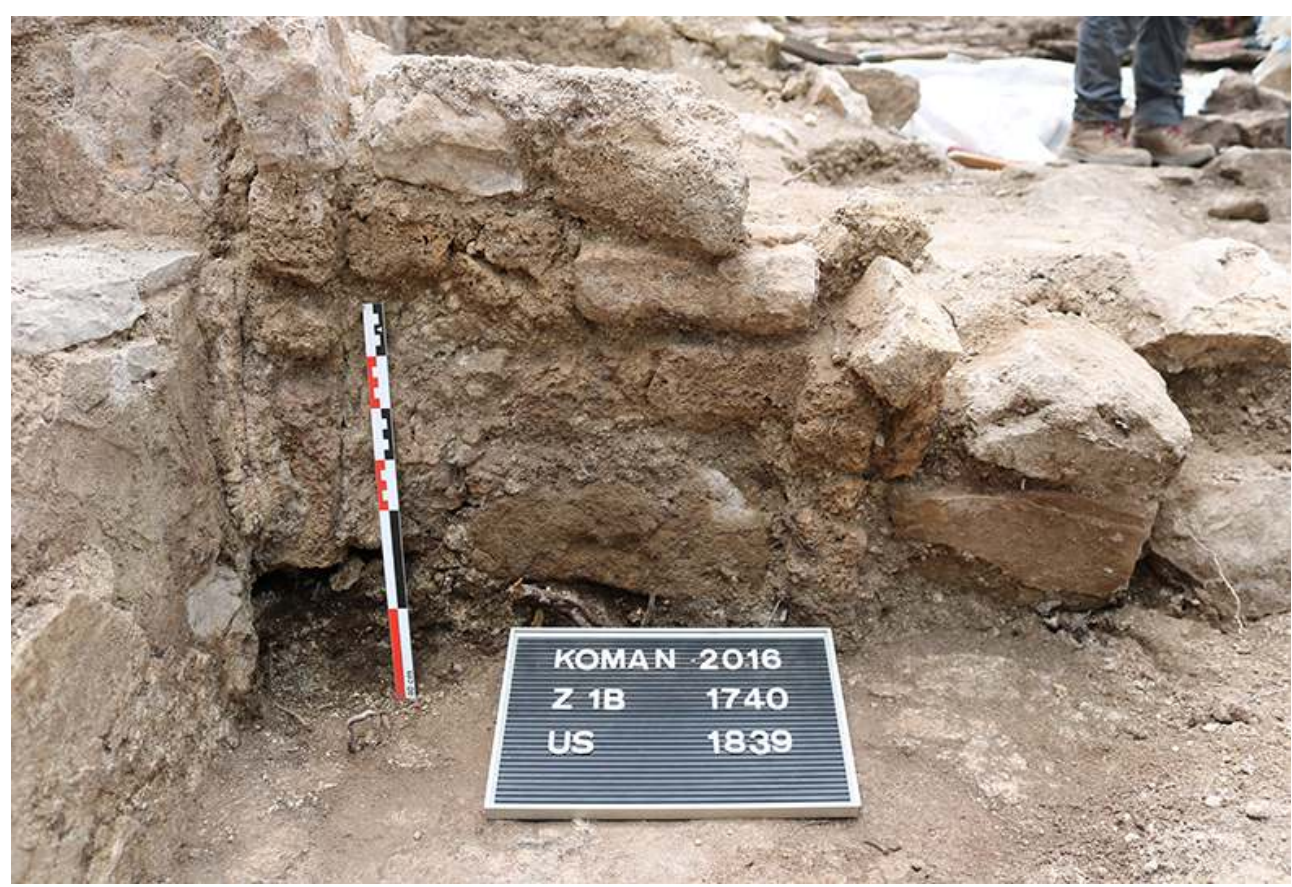

Cl. Y. Bonfand. 
Fig. 33 - Église, zone 1B. Aménagement en tuf, chancel (US 1839).

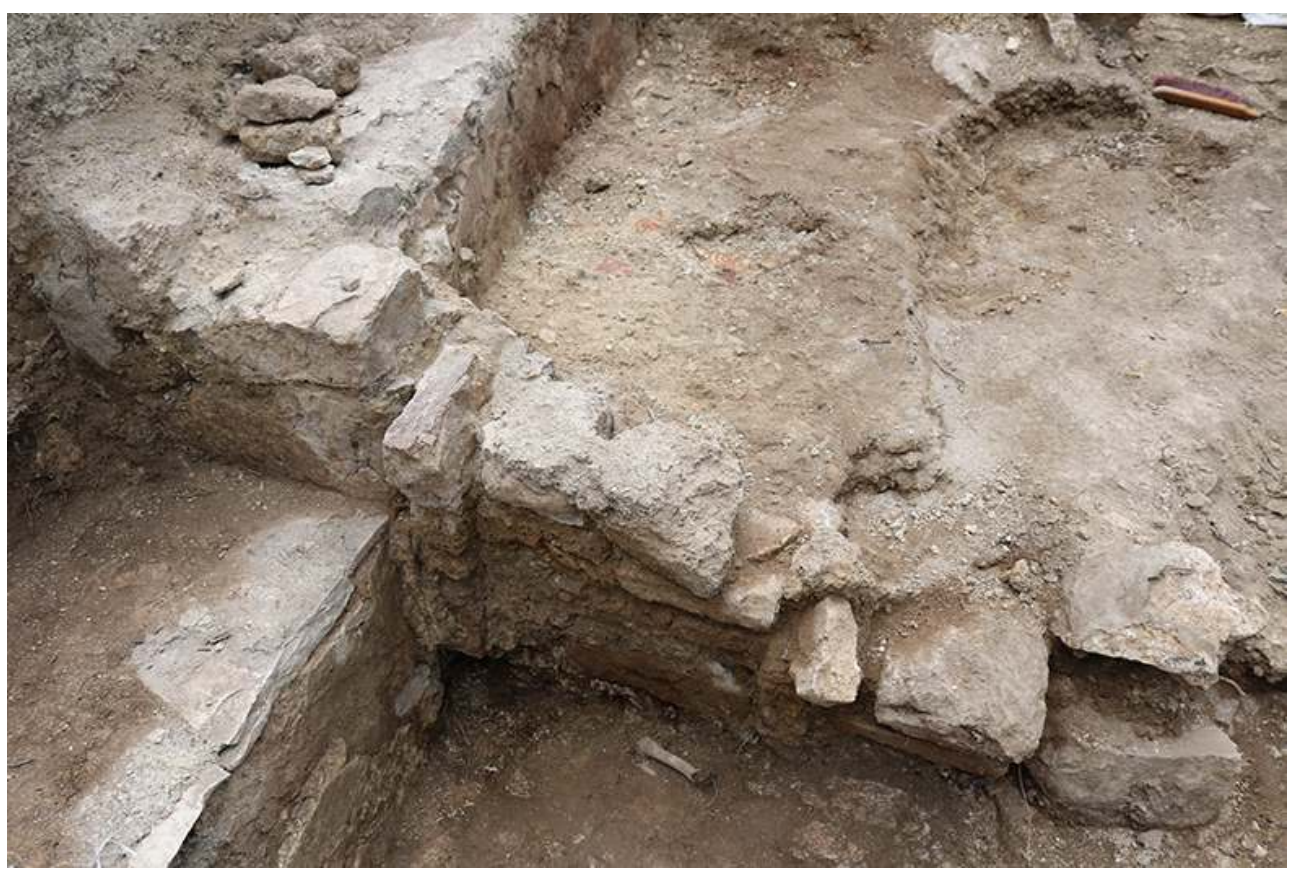

Cl. Y. Bonfand.

\section{Les niveaux de sol}

Deux niveaux de sol sont déjà apparus lors de la précédente campagne, dans le sondage 1740 : l'un précédait la marche 1781 quand l'autre la poursuivait vers l'Est. Par ailleurs, l'entrée principale et toute la moitié ouest de la nef, sont couvertes d'un mortier qui correspondait au niveau de sol 1783 de la nef. Il s'agit de mortier lissé, jointif avec les banquettes et agrémenté de galets. Quelques pierres plates disposées à plat laissent penser à des réfections dans un sol endommagé. Un même mortier a été perçu sur toutes les marches (fig. 27 ; fig. 34-36) ainsi que sur les aménagements 1870 et 1871. 
Fig. 34 - Église, zone 1B. Dalles disposées à plat (dallage ?).

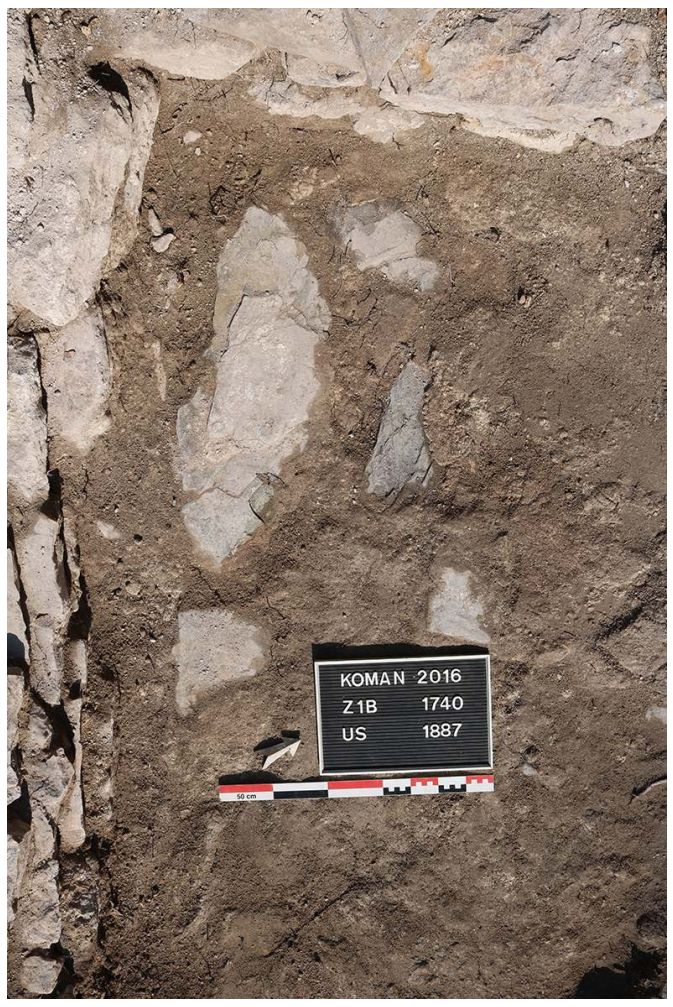

Cl. Y. Bonfand.

Fig. 35 - Église, zone 1B. Affaissement du sol dans l'angle sud-ouest.

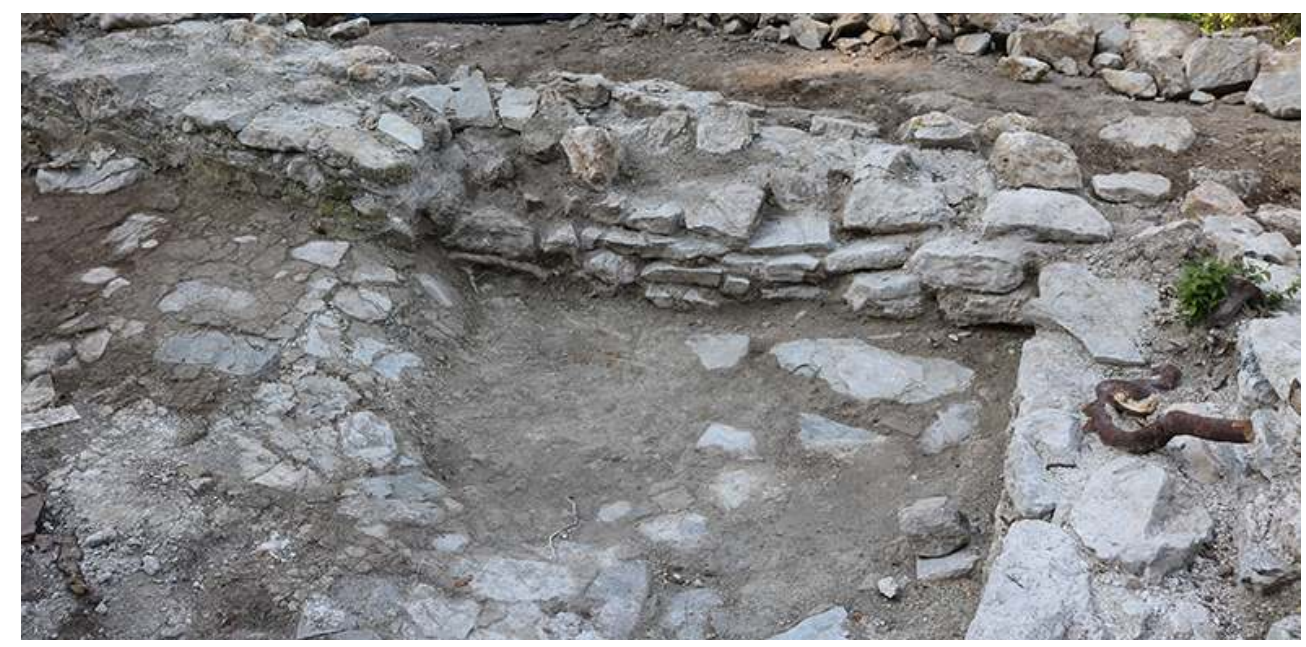

Cl. Y. Bonfand 
Fig. 36 - Église, zone 1B. Niveau de sol 1783 contre banquette 1845.

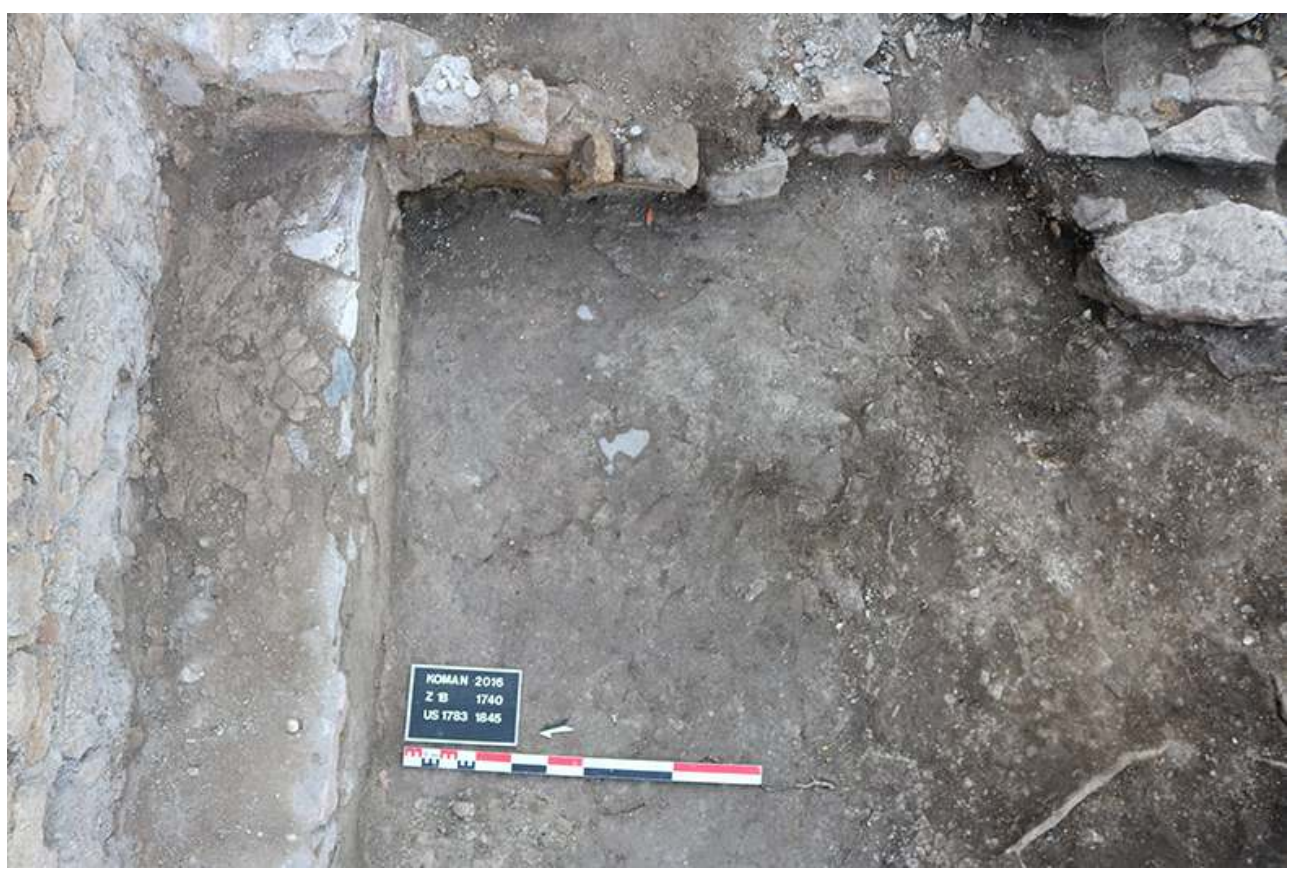

Cl. Y. Bonfand.

Par ailleurs, quelques données - au demeurant peu exploitées - ont permis de suspecter la présence d'autres niveaux de sol dans l'église. Plusieurs couches de mortier superposées (1783 venant sur 1888) observées dans plusieurs endroits, laissent penser à des reprises successives, un entretien général des mortiers de l'église.

\section{Les aménagements liturgiques}

Deux aménagements liturgiques ont déjà été mis au jour en 2014, aux angles sud-est et nord-est de la nef (fig. 37; fig. 48). Une troisième structure -1889- mise que partiellement au jour en 2014 a été identifiée comme un nouvel aménagement liturgique. Localisé sur l'axe central de la nef et précédant l'abside et ses dispositifs, cet aménagement est constitué de nombreux éléments de tuf moulurés liés au mortier ( fig. 38). La forme se présente vaguement rectangulaire avec des éléments de tuf taillés agencés sur une base d'enduit qui repose sur le niveau de sol dans la poursuite de la marche 1838. La position, centrale, la forme, rectangulaire, ainsi que le souci de l'ornementation donnent à penser qu'il s'agit du support pouvant accueillir la table d'autel. 
Fig. 37 - Église, zone 1B. Aménagement liturgique de la partie sud-est - Lavabo droit.

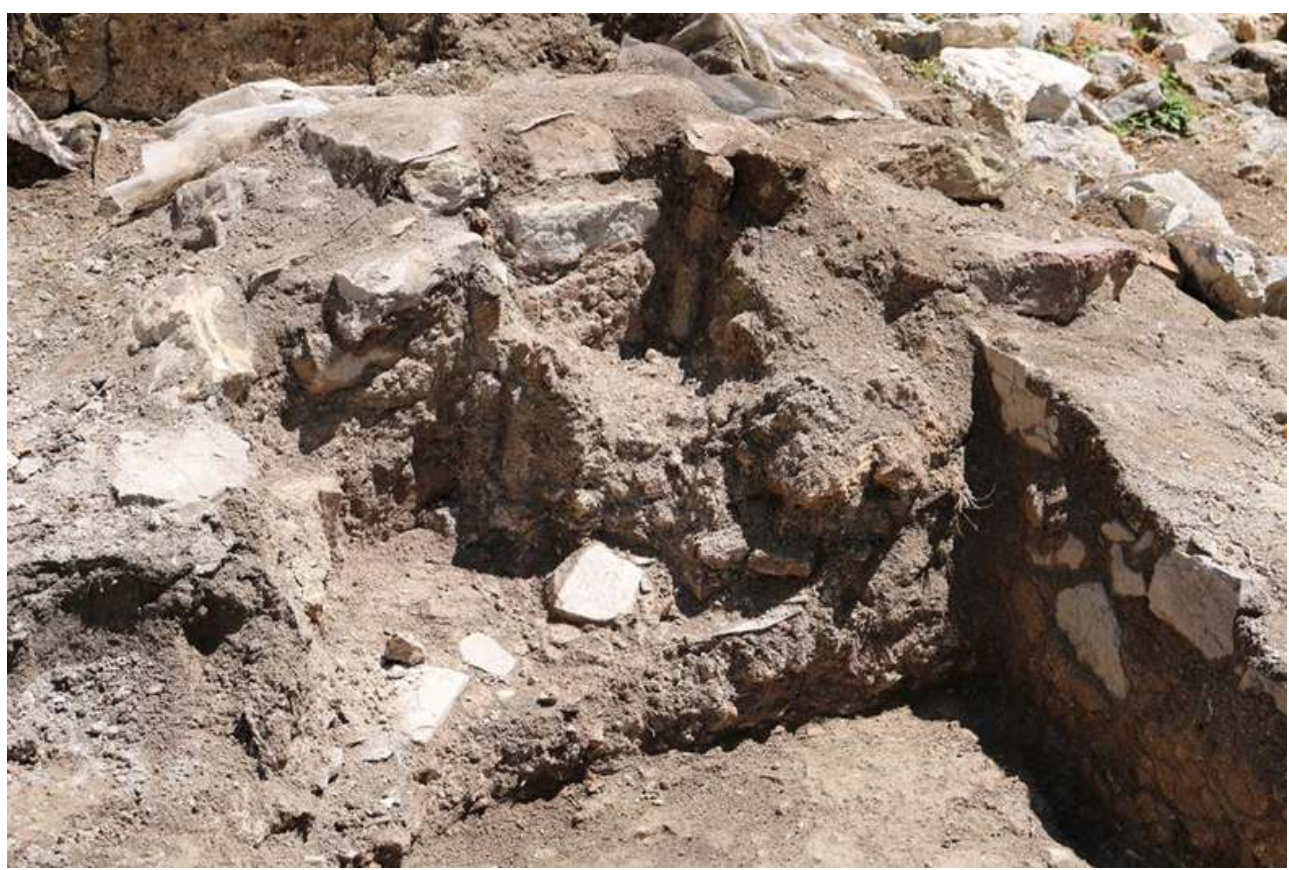

Cl. Y. Bonfand.

Fig. 38 - Église, zone 1B. Aménagement liturgique central.

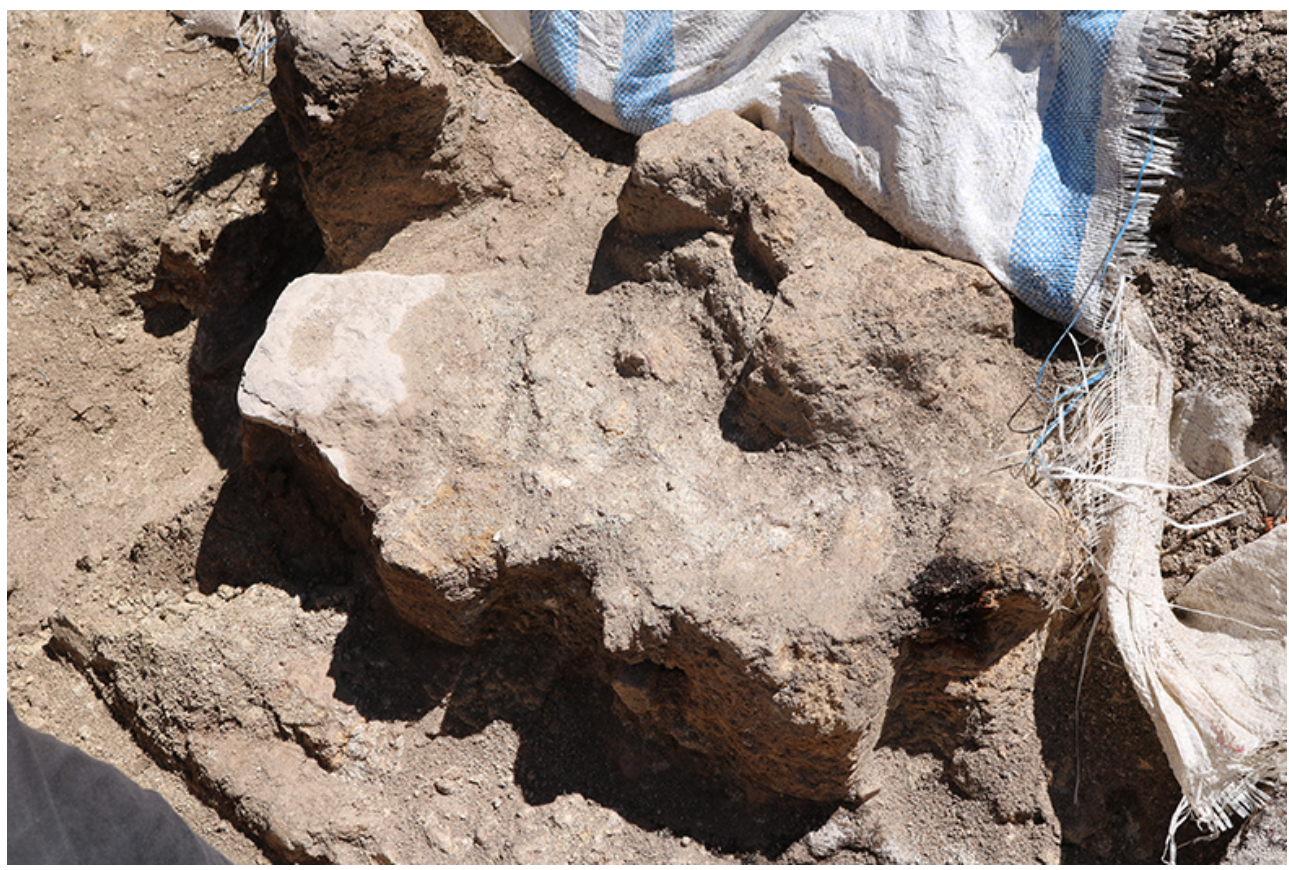




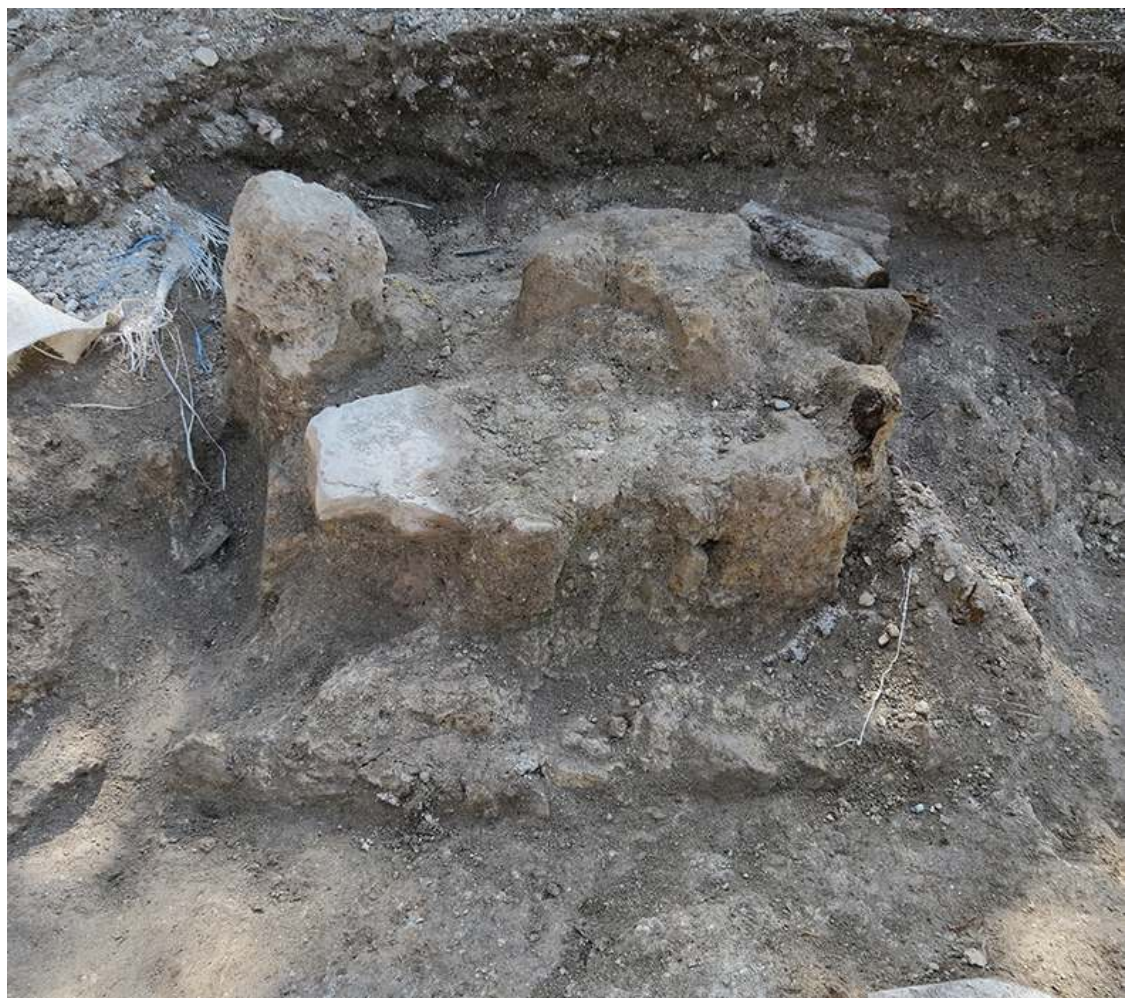

Cl. E. Nallbani.

\section{Décors et ornementation}

Si l'édifice n'a livré qu'un rare mobilier archéologique, la mise au jour d'éléments d'ornementation s'est avérée particulièrement riche. Toutefois, c'est indubitablement au cours de l'opération de 2016 que les principales découvertes, les plus spectaculaires et les plus inattendues, ont été effectuées : la mise au jour de grands fragments d'enduits peints permettant de recomposer des motifs, ainsi que la découverte d'une inscription peinte parmi ces enduits.

\section{Les enduits peints}

La majorité des fragments d'enduits peints, mis au jour pendant les campagnes précédentes, proviennent des murs de l'apside et des angles nord et sud des installations liturgiques.

31 En 2016, des centaines - sinon des milliers - de fragments d'enduits peints, dont l'essentiel issu de destructions trouvées sur la banquette 1846 (US 1830) ou sur le sol de l'église, ont considérablement complété le décor. D'autres secteurs ont livré, eux aussi, de tels éléments picturaux, en quantité moindre cependant.

32 La variété des motifs géométriques les jeux sur l'épaisseur des traits et la gamme des couleurs utilisée attestent de la recherche et du raffinement de ces peintures, réalisées avec finesse (fig. 41). Des ensembles figuratifs sont aussi représentés comme une découverte majeure, située sur un pilier (interprété comme bouchage du mur du collatéral, M50) (fig. 19). Il s'agirait d'une scène représentant l'animal dans la nature ou dans une barque? réalisée avec une technique différente de celles des autres enduits peints et dont la datation serait plus ancienne. 
Fig. 39 - Église, zone 1B. Fragments d'enduit peint avec motif figuré.

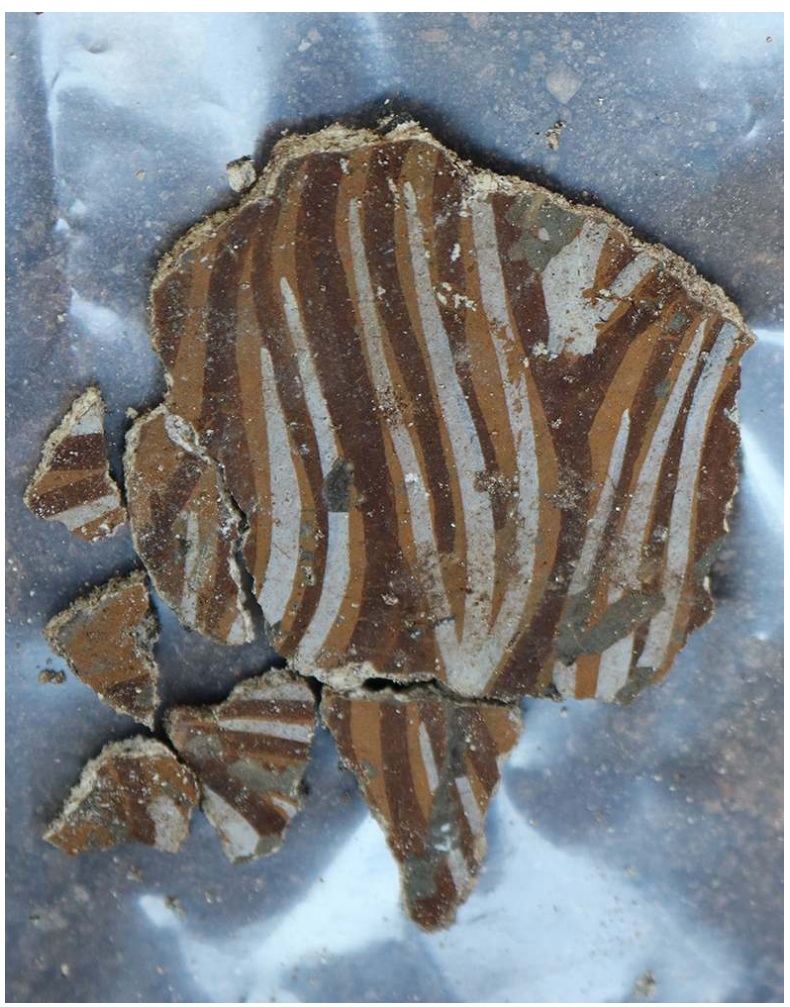

Cl. E. Nallbani.

Fig. 40 - Église, zone 1B. Fragments d'enduit peint avec motifs géométriques.

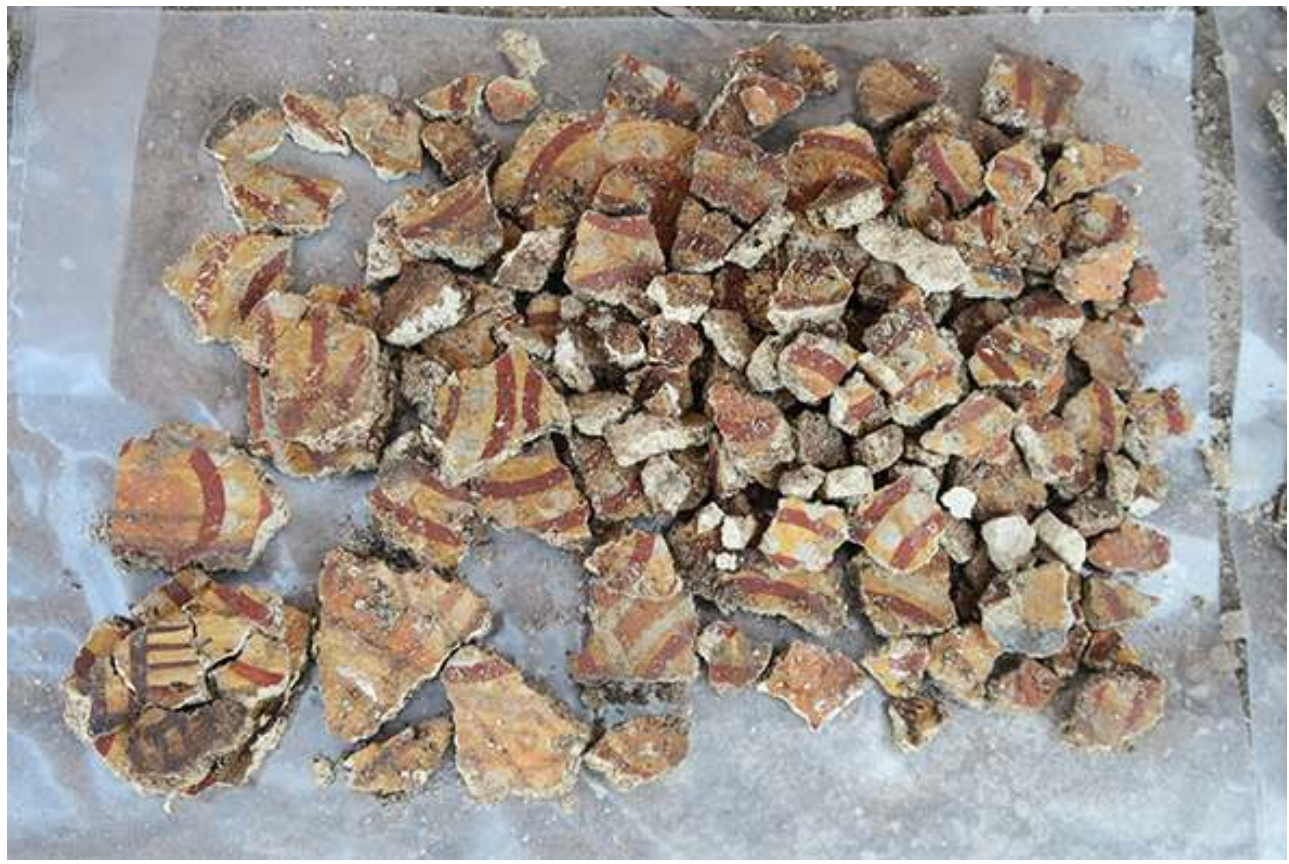

Cl. E. Nallbani. 


\section{Les fragments d'inscription}

Vers le ressaut de la banquette 1891, parmi les niveaux de destruction qui venaient recouvrir les marches 1817 et 1818, furent découverts des fragments d'enduits avec inscription, l'US 1890 (fig. 41), répandue sur un espace limité de $0,40 \times 0,80 \mathrm{~m}$. Trouvés contre le mur M50, ces éléments semblent provenir de ce dernier plutôt que de la banquette. Très nombreux, certains fragments permettent de reconstituer quelques lettres disposées de façon linéaire voire suivant plusieurs registres. Surmontés d'ocelles et encadrés d'aplats de couleurs, les inscriptions sont écrites en lettres majuscules latines noires sur fond blanc, séparées par des lignes droites jaunes (fig. 42).

Fig. 41 - Église, zone 1B. Dégagement des inscriptions contre le mur M50.

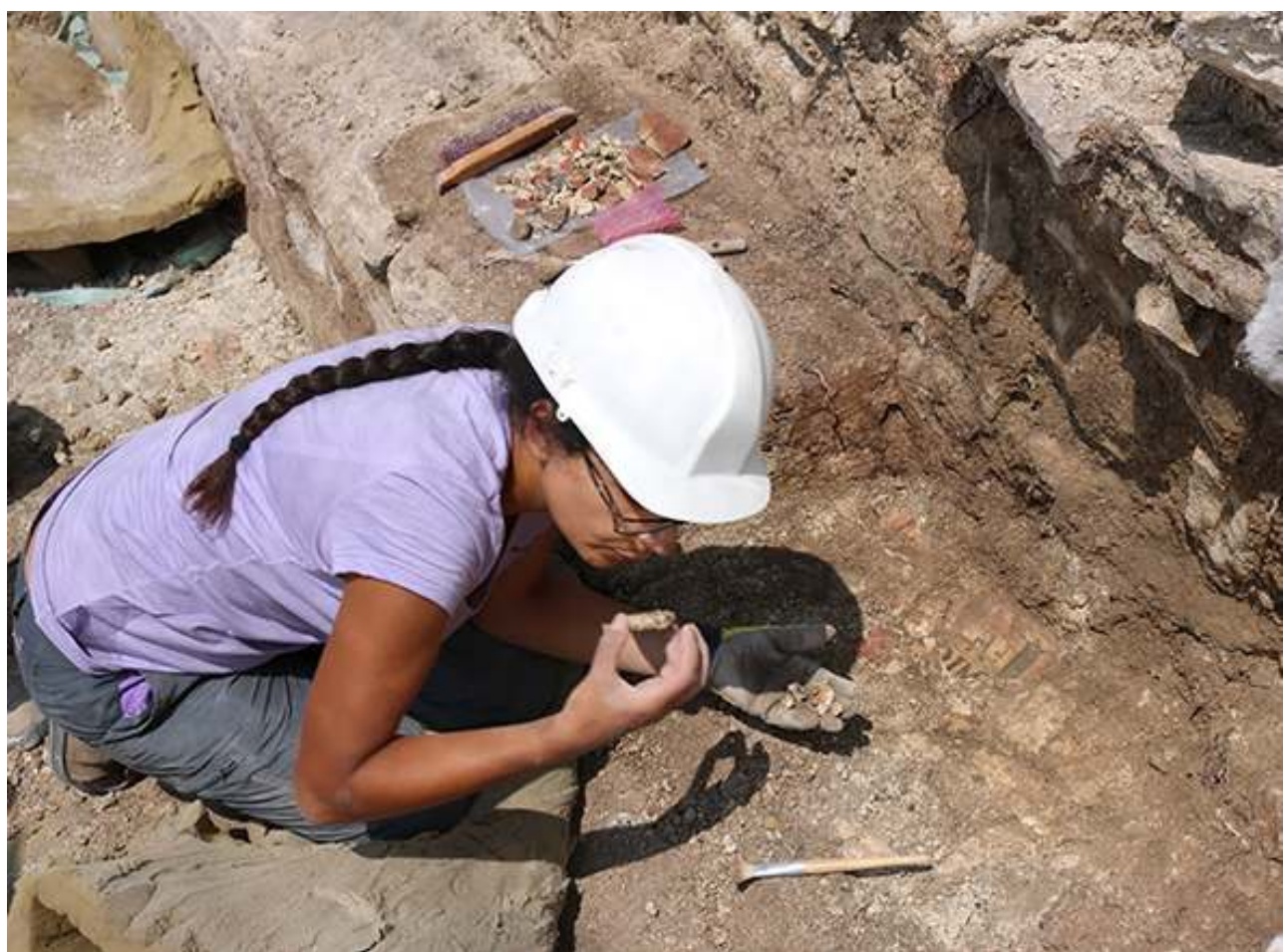

Cl. Y. Bonfand. 
Fig. 42 - Église, zone 1B. Fragments d'enduits avec inscription.

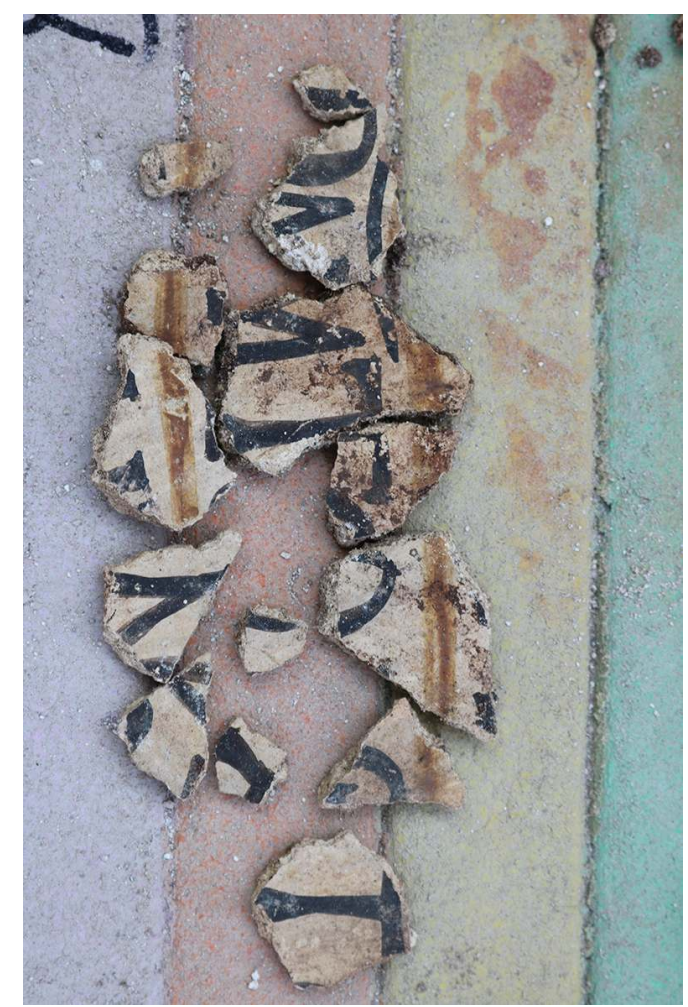

Cl. E. Nallbani.

\section{Le tuf}

Le tuf est très présent dans les niveaux de destruction de l'église. Toutes les installations liturgiques, mises au jour en 2014 et 2016, et surtout l'ensemble de l'espace sacré ont multiplié considérablement les éléments en tuf. Sous forme taillée, les fragments sont utilisés abondement dans l'architecture, la décoration ou en tant qu'éléments structurels d'un petit mobilier liturgique : claveaux, meneaux, impostes et briques ont été mis au jour (fig. 43).

Seul élément notable, la mise au jour de débris de verres dans le collatéral qui attestent d'une fonction d'éclairage, nécessité qui résulte peut-être du comblement des ouvertures du mur M50 (fig. 44). Par ailleurs, quelques clous mis au jour dans les niveaux de destruction des murs - cinq - attestent cependant de la présence d'une charpente en bois, quoiqu'ils se révèlent particulièrement peu nombreux. 
Fig. 43 - Église, zone 1B. Petite « boîte » en tuf, provenant de l'installation liturgique au nord-est de la nef.

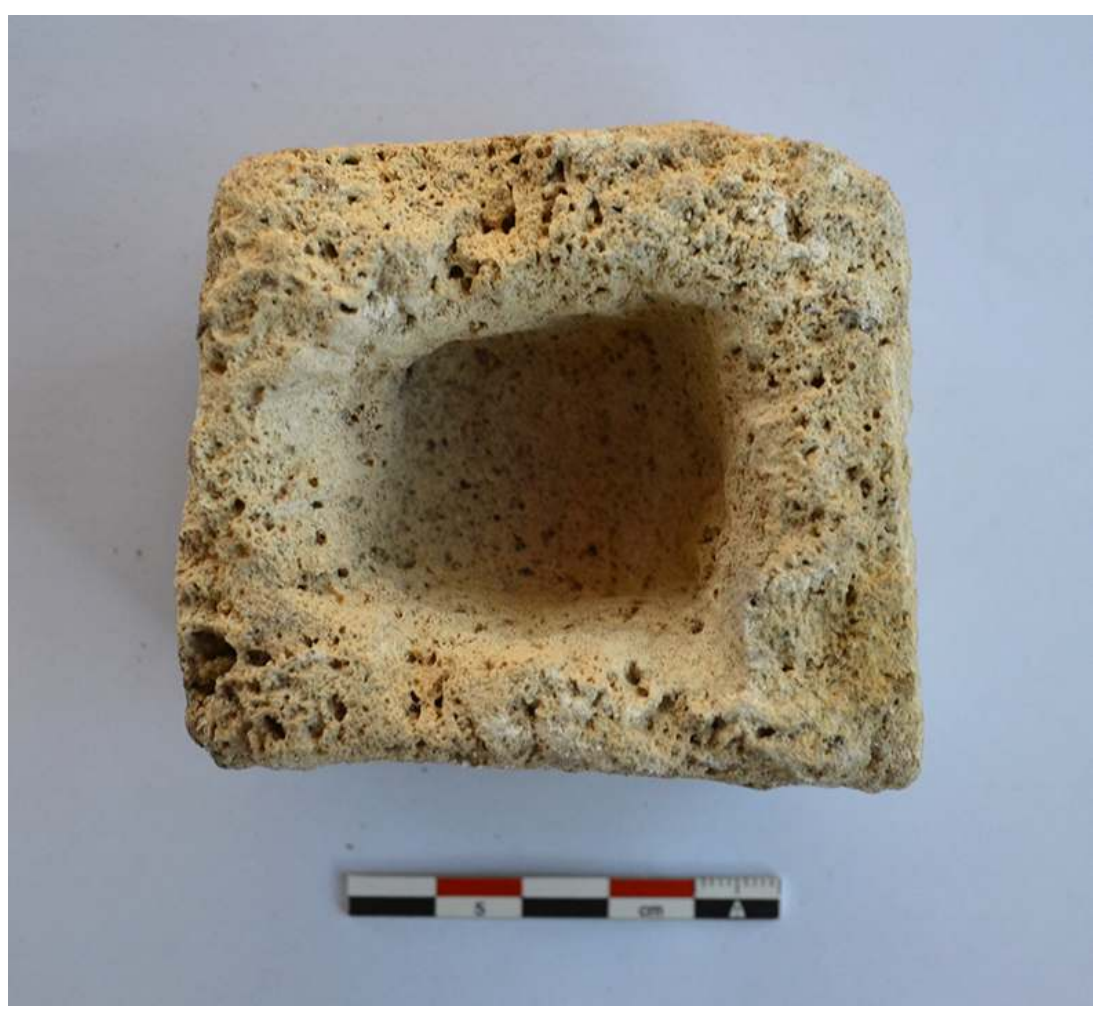

Cl. E. Nallbani. 
Fig. 44 - Église, zone 1B. Fragments de lampes en verre (a, b, d).

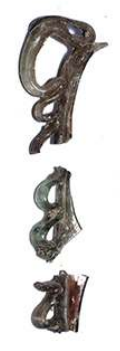

$a$

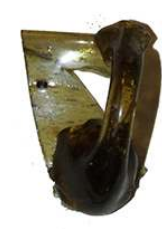

C

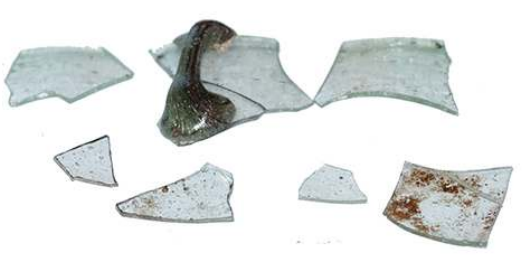

$b$

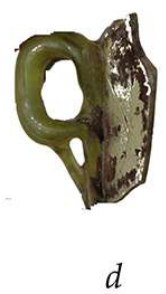

$0 \quad 2 \mathrm{~cm}$

\section{Sépultures en relation avec l'église}

36 À l'espace cimétérial à l'est du chevet, qui a livré dix sépultures, on rajoute les onze sépultures installées dans le collatéral nord. La fouille exhaustive de la nef a aussi mis au jour plusieurs squelettes partiels, en relation avec l'église en ruine ou ses décombres. Une structure funéraire a été pourtant repérée mais pas fouillée, près de l'entrée et sous le niveau du mortier du sol. Il s'agit d'une découverte de dernière minute. On pourrait également affirmer l'usage funéraire de l'espace entre le mur nord du collatéral et la falaise (espace à fouiller aux campagnes suivantes).

\section{Le collatéral nord}

Les niveaux supérieurs de destruction de la moitié est du collatéral, ont livré le squelette d'un enfant (T. 364) (fig. 45). L'inhumation disposée est-ouest dans des décombres collés au mur sud du collatéral pourrait faire appel à l'usage du bâtiment comme un lieu d'inhumation, après sa destruction. 
Fig. 45 - Église, zone 1B. Tombe 364, enfant inhumé dans des décombres, accolé au mur séparant la nef du collatéral.

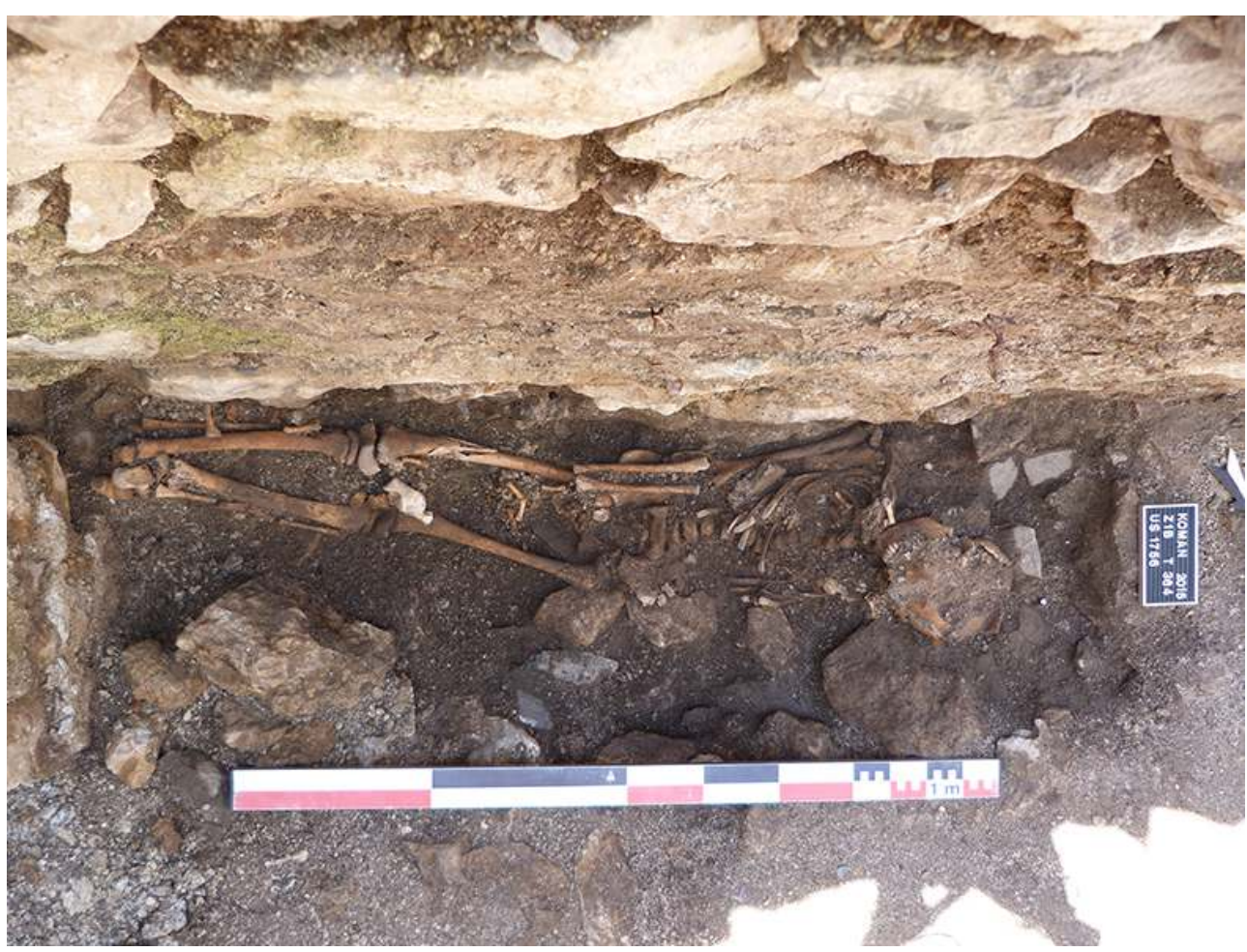

Cl. S. Vatteoni.

fouillées et relevées (fig. 46-47). La grande majorité d'entre elles (à part les tombes 376 et 377) a été bâtie en dalles de schiste (parois et couverture) installées directement sur le rocher en place. Elles sont toutes individuelles, avec la tête déposée à l'ouest et en position de décubitus dorsal. La durée d'utilisation funéraire du collatéral semble avoir été relativement longue, malgré le peu de structures retrouvées: 4 tombes (sur les 6 localisations répertoriées) recoupent des anciennes tombes, attestant ainsi une mauvaise connaissance de l'emplacement des anciennes, ainsi qu'une absence de marques de surface; cependant le recoupement s'est arrêté au niveau de l'apparition des anciennes inhumations en place, les préservant ainsi.

Il semble que l'usage funéraire de l'annexe est assez tardif dans l'utilisation de l'église : les sépultures pour la plupart percent un ou des niveaux de mortier, qui devaient correspondre à un moment donné aux niveaux de sol. C'est particulièrement confirmé pour les tombes 376 et 377 , situées à l'est et à l'ouest du collatéral. Elles se trouvent quasi directement sous le niveau de destruction US 711. Une dernière sépulture (entre les structures T. 376 et T. 379, au nord de la T. 381) reste à fouiller en 2017. Il reste à purger les niveaux intermédiaires afin de définir clairement les relations entre ces tombes et les autres éventuelles utilisations de cette partie de l'église. La zone entre le mur nord et la paroi rocheuse est également à sonder, d'autres sépultures s'y trouvent, dans la continuité de T. 372. 
Fig. 46 - Église, zone 1B. Relevé du collatéral nord avec le positionnement des sépultures fouillées.
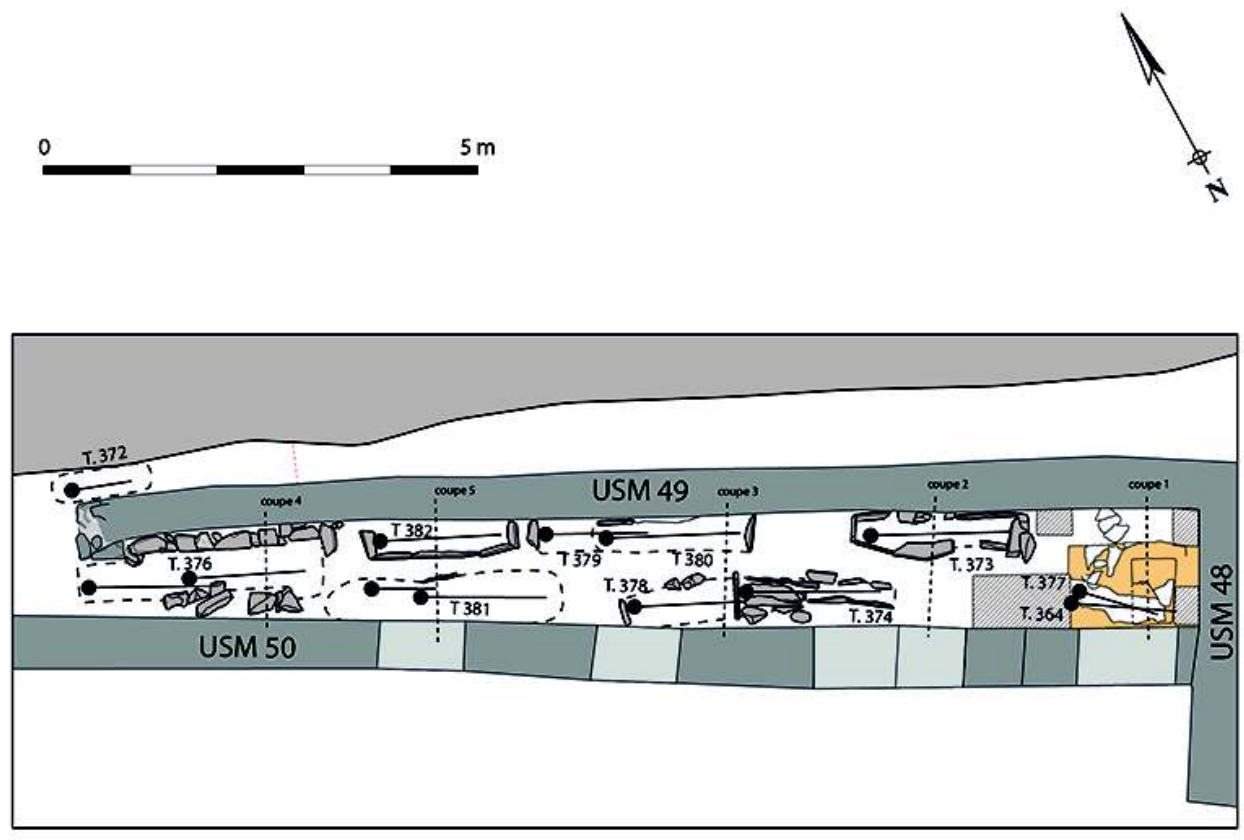

DAO S. Vatteoni.

Fig. 47 - Église, zone 1B. Vue du collatéral depuis l'ouest, avec les sépultures fouillées.

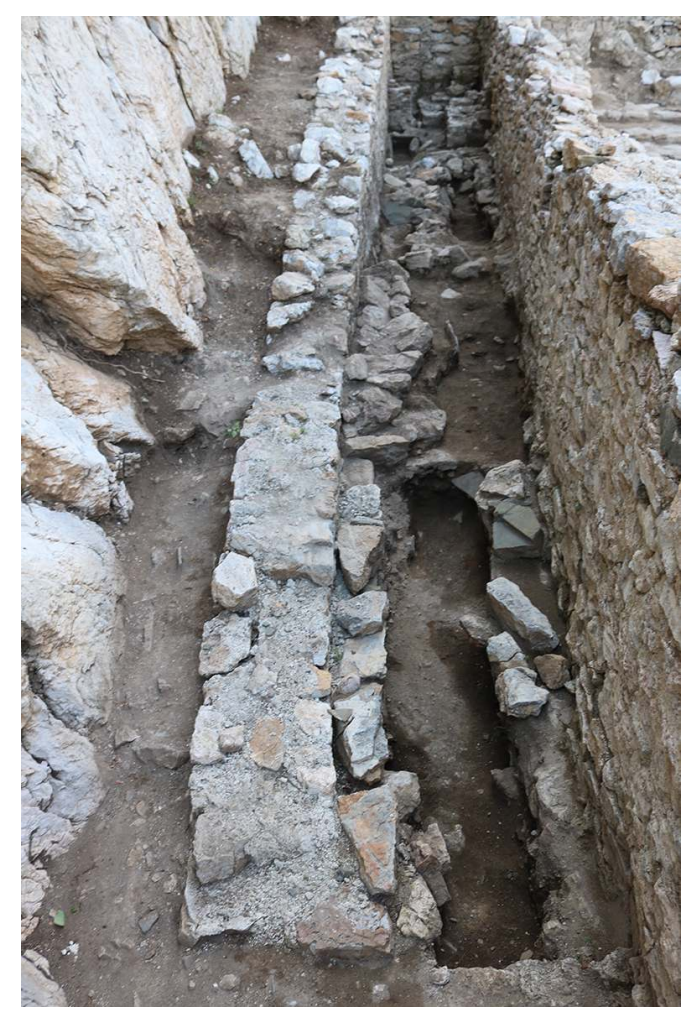

Cl. S. Vatteoni. 


\section{Le nord-est du chevet}

40 Le cimetière au nord-est du chevet, est situé dans une zone très élevée par rapport au niveau de circulation de l'église. Le dénivellement entre le fond des tombes et le seuil de l'église est d'environ $3 \mathrm{~m}$. Son installation a tenu compte du relief naturel, même si au moins une tombe (T.362) a été installée en creusant le rocher. Malgré la densité des sépultures, dans un espace réduit et la superposition sur au moins deux niveaux, des marques de surface, non retrouvées ou non identifiées, auraient dû les signale. Au moins deux tombes ont recoupé les fondations du mur M44, positionné entre le chevet et le bâtiment rectangulaire à l'est.

41 Les cinq sépultures fouillées en 2016 sont des coffres de dalles en ardoise, contenant toutes des inhumations individuelles. En absence absolue de mobilier archéologique, une des deux inhumations de la tombe 363, appartenant au niveau supérieur des sépultures, a été attribuée par datation $\mathrm{C} 14$, à la seconde moitié du XII ${ }^{\mathrm{e}}$ - première moitié du XIII ${ }^{\mathrm{e}}$ siècle.

\section{Hypothèses et interprétations}

La convergence de nombreux indices permet d'affirmer que l'église a été laissée à l'abandon pendant une très longue période. Par ailleurs, bien que les niveaux les plus anciens n'aient pas encore été atteints, il est possible d'émettre une hypothèse de succession d'états.

\section{État 1 : église avec ouvertures sur le collatéral}

Il est possible de proposer, dans un premier temps, une nef dépourvue de ses banquettes et de certaines des marches (1817-1818) - ce qui ne signifie pas que l'église en était dépourvue - avec des baies ouvertes sur le collatéral (voir fig. 17).

Une structure maçonnée dans le collatéral, dont il ne reste que la base et quelques négatifs (US 1897), fonctionnait en lien avec la nef (fig. 21). Le gros pilier débordant sur le collatéral a été mis au jour (fig. 20) et pourrait être associé à cet état puisqu'il est pris en compte lors de l'installation de la structure maçonnée. Le rôle de cet espace ne peut être que conjectural en l'absence, à l'état actuel, de données archéologiques. On serait tenté d'y voir l'installation d'une chapelle latérale ou mieux, d'un autel annexe. Les fragments de vases en verre (fig. 44) ${ }^{1}$, trouvés dans le niveau de destruction de cette structure, mélangés aux fragments de supports finement enduits (probablement d'une table ?), sont en faveur de cette proposition.

Cependant, les niveaux de sol des deux côtés du mur correspondent. Ce qui signifie qu'il fallait que le niveau de circulation dans la nef soit approximativement le même que celui de la marche 1838.

\section{État 2 : reconstruction de piliers avec ajout d'un enduit peint}

Après une destruction ou modification d'un premier pilier débordant dans le collatéral, celui-ci est reconstruit en deux éléments. Aucun indice ne permet de proposer de 
chronologie relative entre les deux. Quoi qu'il en soit une peinture les lie ensemble (voir fig. 19). dans la relation des espaces souligne peut-être l'accession du collatéral à un rôle funéraire. Une dizaine de sépultures coupent les niveaux de sols qui étaient jointifs avec la nef ou les aménagements spécifiques du collatéral à l'instar de son accès ouest.

\section{État 5 : toute l'église est recouverte de mortier oblitérant les enduits peints.}

51 Les continuités attestées entre les sols et banquettes ainsi qu'entre les banquettes et murs attestent que dans un dernier état avant abandon, toute l'église a été une ou plusieurs fois enduite d'une épaisse couche de mortier. Cette dernière est venue harmoniser tous les volumes et oblitérer toutes les décorations. Le tuf n'était certainement pas épargné comme le montrent les divers dépôts de mortier que l'on peut observer sur chacune des faces de certains éléments.

Cette proposition de succession d'états est fragile et repose essentiellement sur une volonté de rationalisation des vestiges observés. Il convient d'enrichir la réflexion au cours des campagnes futures afin de valider ou d'invalider ces observations pour affiner la connaissance de l'église.

\section{Conclusion}

La fouille de 2016 complète et achève la grande entreprise de dégagement de l'église initiée en 2014. Ignorée depuis plusieurs siècles sous les débris d'une falaise qui l'a progressivement engloutie, elle s'est imposée comme l'un des vestiges architecturaux 
majeurs du site. Aussi, loin d'être épuisés, les interrogations qu'alimentent la structure et la taille de l'église, son implantation, son évolution et ses décors et son rôle au sein de la communauté médiévale sont d'un intérêt majeur pour la compréhension de l'occupation de Koman. Car, à n'en pas douter, son occupation fut longue et certainement chaotique. Les enduits richement colorés rayonnent d'autant plus que le contraste est saisissant visà-vis des couches de mortiers qui les recouvrent. Peut-être faut-il voir dans ses périodes plus austères d'un point de vue pictural l'évolution de ses attributions, ou bien d'un point de vue économique, l'appauvrissement de la communauté.

Toutefois, si la fouille a permis d'avancer exceptionnellement dans la connaissance de l'église, de nombreux points demeurent énigmatiques. Si la poursuite de la fouille permet de comprendre les relations et les aménagements présents au niveau de l'abside, la compréhension de la partie centrale quant à l'organisation de la première marche est encore à établir.

Fig. 48 - Église, zone 1B. Plan général des vestiges 2016.

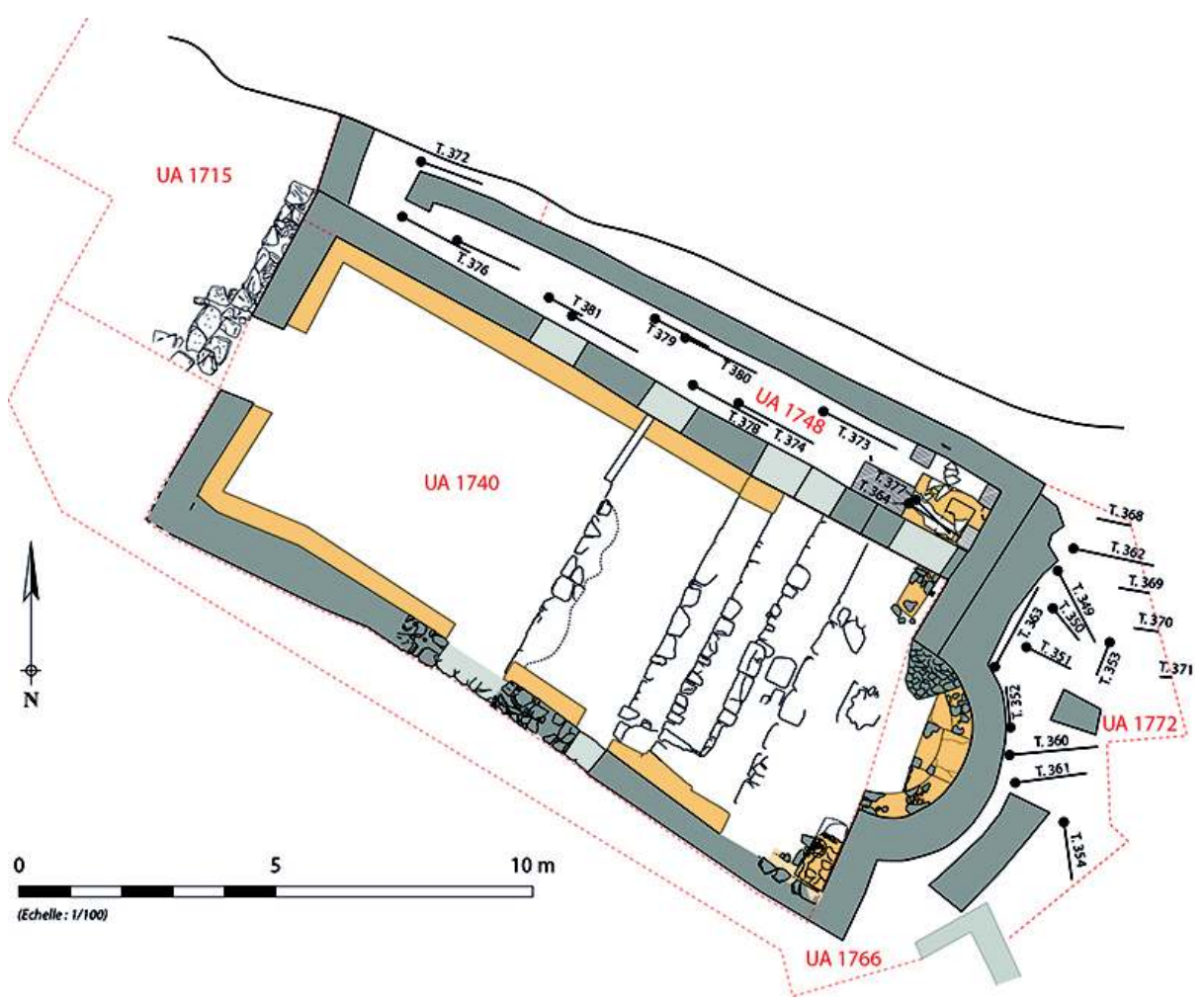

DAO Y. Bonfand et S. Vatteoni.

\section{Sépulture isolée}

Une tombe isolée, T. 375, a été identifiée sur le chemin reliant la « forteresse » de Dalmace avec le village de Saint-Nicolas, correspondant au flanc nord-est de la nécropole principale du site (zone archéologique 2). Partiellement visible, la fouille de la structure était devenue nécessaire à cause des menaces liées à la destruction et au pillage.

Il s'agit d'un coffre de dalles en schiste (parois posées de chant et couverture à plat), 2,10 $\mathrm{m}$ de longueur pour 0,55 $\mathrm{m}$ de largeur, aménagée dans une fosse, orientée est-ouest. Le coffre à usage multiple contenait onze défunts dont huit adultes et trois enfants ( 
fig. 49). Le riche mobilier funéraire : boucles d'oreille, anneau, bagues, collier de perle de verre (fig. 50), dateraient assez large, du $\mathrm{VIII}^{\mathrm{e}}$ au $\mathrm{XI}^{\mathrm{e}}$ siècle. Il nous est impossible d'attribuer ce mobilier à un au plus d'individus précis. L'exception fait un individu, parmi les plus anciennement inhumés, qui portait à son doigt, une bague en bronze représentant un aigle gravé. La datation par $\mathrm{C} 14$ a daté l'inhumation au $\mathrm{X}^{\mathrm{e}}$ siècle.

Fig. 49 - Tombe 375. Flanc nord-est de la nécropole.

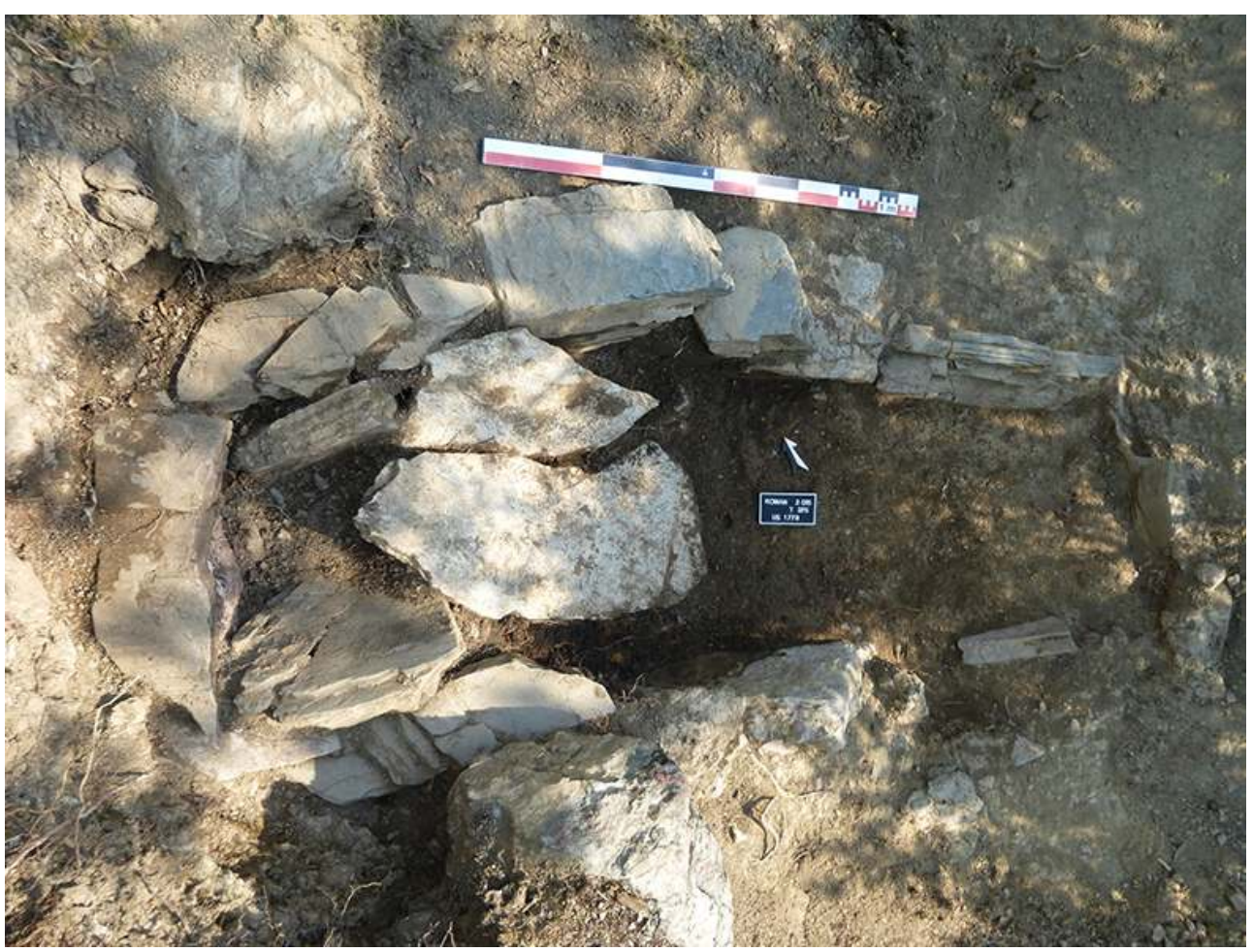

Cl. U. Tota. 
Fig. 50 - Mobilier de la tombe 375.

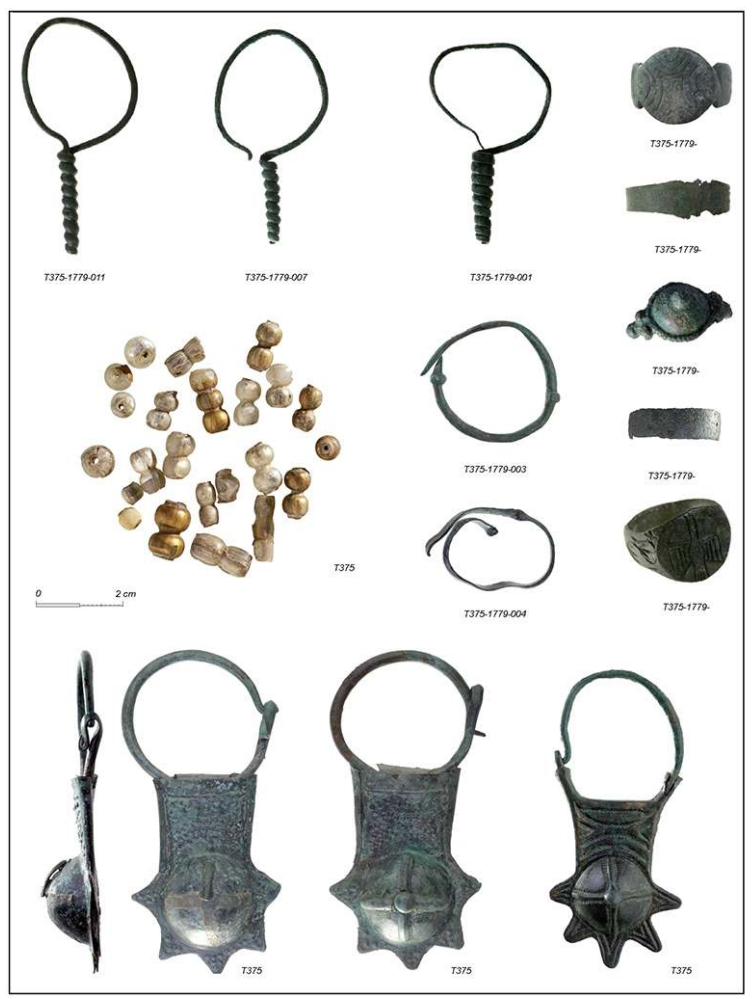

Cl. D. Dubois, dessin E. Cenolli, DAO S. Vatteoni.

\section{NOTES}

1. L'analyse préliminaire réalisée par Elisabetta Neri identifie trois lampes différentes dont la typologie reste assez large $\mathrm{du} \mathrm{V}^{\mathrm{e}}$ au XI $\mathrm{XI}^{\mathrm{e}}$ siècle, mais les analyses chimiques les orientent vers une date post VIII ${ }^{\mathrm{e}}$ siècle.

\section{INDEX}

\section{Index géographique : Komani}

institutions École française de Rome ; Institut d'Archéologie de Tirana ; UMR 8167, Orient et Méditerranée ; Labex RESMED ; UMR 7264, CEPAM.

Mots-clés : Albanie, Komani, haut Moyen Âge, archéologie, église, collatéral, tombe, synthronon, lavabo liturgique, enduits peints, lampe en verre 


\section{AUTEURS}

\section{ETLEVA NALLBANI}

CNRS, UMR 8167/Orient et Méditerrané, Paris - etleva.nallbani@college-de-france.fr

\section{YANN BONFAND}

Université Grenoble-Alpes (LUHCIE), chercheur associé à l'ARAR (UMR 5138) yann.bonfand@laposte.net

\section{SOPHIE VATTEONI}

Communauté d'agglomération de Douaisis-DAP - svatteoni@hotmail.fr

\section{ELVANA METALLA}

Institut d'Archéologie de Tirana - emetalla@hotmail.com 